\title{
Die Reform der direkten Demokratie in Berlin 2006 (Teil II)
}

\section{Otmar Jung}

Teil I dieser Studie behandelte den Reformprozeß $2006^{*}$. Nun folgt in Teil II die inhaltliche Beurteilung der Reform.

\section{Die Beurteilung der Reform}

\subsection{Grundsätzliches}

Wie ist diese Reform inhaltlich zu beurteilen? Die rasch getroffenen Pauschaleinschätzungen führen dabei nicht weiter: daß die Volksgesetzgebung damit „spürbar erleichtert“ werde ${ }^{1}$ oder daß es zwar für Platz 1 im Ländervergleich noch „nicht ganz“ reiche, aber Berlin immerhin „die rote Laterne“ abgegeben habe $^{2}$. Vielmehr sind zunächst die einzelnen Reformschritte zu untersuchen und abzuwägen. Maßstäbe dafür sind zum einen - innerberlinisch - der Status quo ante und die praktischen Erfahrungen mit ihm, der PDS-Entwurf vom September 2000, der Grünen-Entwurf vom November 2005 und der Entwurf des Bündnisses für Direkte Demokratie vom März 2006 (von SPD, CDU und FDP liegen in diesem Zeitraum keine vergleichbar ausgearbeiteten Positionen vor), zum anderen komparatistisch - der innerdeutsche Vergleich und der internationale Standard sowie grundsätzliche theoretische Überlegungen. Erst danach ist eine zusammenfassende Beurteilung möglich. Schließlich soll die Reform nicht nur im „technischen“ Sinne als Verfassungsänderung analysiert, sondern es soll auch der politische Stil dieser Reform - mit einem großen Wort: ihr Geist - gewürdigt werden.

O. Jung, Die Reform der direkten Demokratie in Berlin 2006 (Teil I), in: JdD 3 (2011), S. 259-294.

1 U. Zawatka-Gerlach, Regierender wird mächtig wie ein Ministerpräsident, in: Der Tagesspiegel (Tsp.) Nr. 19175 v. 28.4.2006.

2 Abg. Klaus Lederer (Linkspartei.PDS), Abgeordnetenhaus (AH) 4.5.2006, S. 7341 D. 


\subsubsection{Die Erleichterung der Einwohnerinitiative}

Statt wie bisher von 90.000 volljährigen Einwohnern muß eine Einwohnerinitiative künftig nur von 20.000 Einwohnern der Stadt, die mindestens 16 Jahre alt sind, unterzeichnet sein (Art. 61 Abs. 1 S. 2 Verfassung von Berlin [VvB] n.F.). Die Grünen (2005) und das Bündnis (2006) hatten hier sogar 10.000 Unterschriften genügen lassen wollen. Aber auch die beschlossene Senkung auf 20.000 Unterschriften - übrigens der Wert, für den die PDS 2000 plädiert hatte - bringt gewiß eine deutliche Erleichterung ${ }^{3}$, zumal ja nicht nur die Hürde drastisch ermäßigt, sondern auch der Kreis der Berechtigten erweitert wurde. Indes ist nicht zu vergessen, daß die alte Hürde „unangemessen“ war ${ }^{4}$. Der Verfassungsgeber hatte die Latte von vornherein auf einen vergleichsweise ,überhöhten Wert" gelegt ${ }^{5}$. Warum vor diesem vergleichsweise schwachen direktdemokratischen Instrument 1995 eine solche Hürde aufgerichtet wurde, ist unerfindlich ${ }^{6}$. Wie überzogen die alten Anforderungen waren, zeigt auch das Beispiel des benachbarten Brandenburgs, in dem die Zustimmung von (umgerechnet) knapp vier Prozent der Berechtigten (hier: Stimmbürgerinnen und Stimmbürger) bereits für ein Volksbegehren ausreicht ${ }^{7}$, während Berlin für eine bloße Einwohnerinitiative die Unterstützung von (umgerechnet) 3,2 Prozent der Berechtigten (hier: volljährige Einwohner) verlangte. Nachdem inzwischen auch Hamburg (2001) und Thüringen (2003) die Hürden auf dieser ersten Verfahrensstufe halbiert ${ }^{8}$ bzw. mehr als halbiert ${ }^{9}$ haben und Nordrhein-Westfalen (2002) von vornherein eine niedrige

So Drs. $15 / 5038$ v. 26.4.2006, S. 6 (Begründung zu Art. I Nr. 7).

So die Grünen, vgl. Drs. 15/4472 v. 16.11.2005, S. 2 (Begründung zu Art. I Nr. 1).

Vgl. O. Jung, Abschluß und Bilanz der jüngsten plebiszitären Entwicklung in Deutschland auf Landesebene, in: JöR 48 (2000), S. 39-85 (79).

Zur Entstehung dieser Hürde vgl. Jung, a.a.O., S. $61 \mathrm{f}$.

Auch wenn bislang erst ein einziges Volksbegehren zustande kam, kann der direkten Demokratie in Brandenburg nach der Verfassungspraxis durchaus ein gutes Zeugnis ausgestellt werden. Die repräsentativ-demokratische Politik wird nämlich in Brandenburg responsiver betrieben, vgl. O. Jung, Die Gesetzgebung wird durch Volksentscheid und durch den Landtag ausgeübt - Parlamentarismus und direkte Demokratie auf gleicher Augenhöhe?, in: L. Bisky/H. Vietze (Hrsg.), Reformbedarf einer modernen Verfassung. Kolloquium der Fraktion der PDS zum 10. Jahrestag der Verfassung Brandenburgs, Potsdam 2002, S. 74-97 (83-87).

8 Von 20.000 auf 10.000 Stimmberechtigte (Art. 50 Abs. 1 S. 3 Verf.), vgl. R.-D. Klooß, Die Reform der Volksgesetzgebung 2001: Niedrigere Quoren und mehr Verfahrensflexibilität, in: H.P. Bull (Hrsg.), Fünf Jahre direkte Bürgerbeteiligung in Hamburg - unter Berücksichtigung von Berlin und Bremen, Hamburg 2001, S. 96-100.

Von sechs Prozent der Stimmberechtigten, d.h. von (zur Zeit des Volksentscheids über die Verfassung 1994) 117.252 auf 50.000 Stimmberechtigte (Art. 68 Abs. 3 Verf.). Vgl. 
Hürde aufgerichtet hat, liegt Berlin mit diesem Reformschritt einfach im Trend und belegt, indem es die Unterstützung durch etwa 0,7 Prozent der Berechtigten fordert, einen der vorderen Plätze: Nordrhein-Westfalen z.B. läßt 0,5 Prozent (allerdings der Stimmberechtigten) genügen ${ }^{10}$.

Eine wichtige Erleichterung bedeutet auch die Streichung der bisherigen Tabus (,Initiativen zum Landeshaushalt, zu Dienst- und Versorgungsbezügen, Abgaben, Tarifen der öffentlichen Unternehmen sowie Personalentscheidungen sind unzulässig“, Art. 61 Abs. 2 VvB a.F.). Auch hier fragt man sich natürlich, ob die alte Regelung nicht von Beginn an verfehlt war. Warum sollte eine Einwohnerinitiative, die zunächst nur ein allgemeines Recht darstellt, das Abgeordnetenhaus mit einem bestimmten Gegenstand der politischen Willensbildung zu befassen, und im besonderen den Vertretern der Initiative noch das Recht auf Anhörung in den zuständigen Ausschüssen gibt (Art. 61 Abs. 1 S. 1 u. 3 VvB), überhaupt mit derartigen Tabus belegt werden? Als „überflüssig“ haben die Grünen diesen Ausschlußkatalog denn auch bündig bezeichnet ${ }^{11}$.

Werden diese Änderungen die Einwohnerinitiative aus ihrem „Schattendasein“ befreien, wie das Bündnis hoffte ${ }^{12}$ ? Die Untersuchung des einzigen Praxisfalls seit 1995 - der Volksinitiative gegen den Bau des Transrapids Berlin-Hamburg (1998) - deutet eher darauf hin, daß das Abgeordnetenhaus an einem Nebenschauplatz reformiert hat. 90.000 Unterschriften volljähriger Einwohner beizubringen war für die Initiatoren damals gerade kein Problem, vielmehr zeigte sich im weiteren Verlauf der politischen Auseinandersetzung ein ,institutionelles Fehlarrangement": Die Einwohnerinitiative ist in Berlin isoliert. Wenn das Parlament dem vorgebrachten und erörterten Anliegen nicht Rechnung trägt, können die Initiatoren nicht etwa zur nächsten logischen Etappe der direktdemokratischen Willensbildung - dem Volksbegehren - weitergehen, sondern das Verfahren ist dann erst einmal zu Ende. Gewiß steht es den Initiatoren auch frei, ein Volksbegehren anzustreben, aber dafür müssen sie gleichsam wieder bei Null beginnen, also Unterschriften für einen Zulassungsantrag sammeln usw.; die für

zur Vorgeschichte O. Jung, Direkte Demokratie in Thüringen: Der Freistaat im Ranking der Bundesländer, in: ThürVBl. 2002, S. 269-278 (270).

10 Art. 67a Abs. 2 S. 1 Verf. NRW. 0,5 Prozent der Stimmberechtigten entsprechen etwa 66.000 Unterstützern, vgl. P. Neumann, Reform der sachunmittelbaren Demokratie in der Verfassung des Landes Nordrhein-Westfalen, in: NWVBl. 2003, S. 1-8 (5); zur Kritik der Ausgestaltung der Volksinitiative: a.a.O., S. 7.

11 Vgl. Drs. 15/4472 v. 16.11.2005, S. 3 (Begründung zu Art. I Nr. 1). Ihre Maxime lautete: „Alles, was Berlin betrifft und in die Zuständigkeit des Abgeordnetenhauses fällt, soll von den Einwohnerinnen und Einwohnern auf die Tagesordnung des Landesparlaments gesetzt werden können."

12 Berlin wird demokratischer. Ein Kommentar zur Reform von Volksinitiative, Volksbegehren und Volksentscheid, http://www.du-entscheidest-mit.de/fileadmin/berlin/pdf/kommentar_zur_reform.pdf (Zugriff 10.9.2006). 
die Einwohnerinitiative gesammelten Unterschriften sind jedenfalls verloren. „So ist die Volksinitiative in Berlin letztlich drucklos und steht damit in der Gefahr, nicht recht ernstgenommen zu werden.“13 Die „Entwertung“ des Instruments der Initiative durch ihre Isolierung vom Gesetzgebungssystem ${ }^{14}$ ist freilich keine Berliner Spezialität; sie ist auch in sechs anderen Bundesländern festzustellen $^{15}$.

Die PDS hatte schon 2000 diesen Kern des Problems getroffen mit ihrem Vorstoß, zu einem echten dreistufigen Volksgesetzgebungsverfahren überzugehen ${ }^{16}$. Während des Reformprozesses griff das Bündnis diese Lösung auf mit seinem Vorschlag, unabhängig von dem fortbestehenden und zu erleichternden „Einwohnerantrag“ eine echte „Volksinitiative“ einzuführen. Diese sollte „optional“" sein, d. h. sie müßte nicht zwingend einem Volksbegehren vorausgehen. Wenn die Initiatoren sich aber für eine Volksinitiative entschieden hätten, sollten sie von ihr - als der „erste(n) Stufe der Volksgesetzgebung“ - zu einem Volksbegehren weitergehen (,hochschalten“) können ${ }^{17}$. Warum diese Anstöße von den (anderen) Parteien nicht aufgegriffen wurden, ist nicht bekannt.

Eine mittelbare Stärkung erfuhr das Instrument der Einwohnerinitiative noch dadurch, daß die Reformer einen Fehlanreiz im System der direktdemokratischen Beteiligungsrechte beseitigten. Für das alte Recht galt ja: „Wenn man mit 25.000 Unterschriften einen Zulassungsantrag für ein Volksbegehren stellen kann, das, weil sich der Schatten des erzwingenden Volksentscheids abzeichnet, richtigen Druck erzeugt, ist es müßig, 90.000 Unterschriften für eine Volksinitiative zu sammeln, die und mit der man vom Parlament nicht ernstgenommen wird. “18 Die

Vgl. O. Jung, Dreimal Fehlschlag. Die schwierigen Anfänge der direkten Demokratie in Berlin, in: ZParl 32 (2001), S. 33-57 (38).

14 A. Ziekow, Direkte Demokratie in Berlin. Entwicklung und Ausgestaltung eines ungeliebten Modells, in: LKV 1999, S. 89-94 (94).

15 In Bremen („Bürgerantrag“, Art. 87 Abs. 2 Verf.), Mecklenburg-Vorpommern (Volksinitiative, Art. 59 Verf.), Niedersachsen (Volksinitiative, Art. 47 Verf.), Nordrhein-Westfalen (Volksinitiative, Art. 67a Verf.), Sachsen-Anhalt (Volksinitiative, Art. 80 Verf.) und Thüringen (,Bürgerantrag“, Art. 68 Verf.), vgl. B.M. Weixner, Direkte Demokratie in den Bundesländern. Verfassungsrechtlicher und empirischer Befund aus politikwissenschaftlicher Sicht, Opladen 2002 (Forschung Politikwissenschaft Bd. 162), S. 107 f., die aber Rheinland-Pfalz zu Unrecht hierher zählt (vgl. Art. 108a Abs. 2 S. 3 Verf.). Ihre Untersuchung wurde vor der Reform in Nordrhein-Westfalen abgeschlossen.

16 Drs. 14/655 v. 14.9.2000, S. 3 (Begründung zu Art. 62 Abs. 1).

17 Vgl. Bündnis für Direkte Demokratie, Entwurf eines Gesetzes zur Änderung der Verfassung von Berlin (9.3.2006), http://www.du-entscheidest-mit.de/fileadmin/berlin/pdf/gesetzentwurf-direkte-demokratie-berlin.pdf (Zugriff 8.9.2006), Nr. 4, Vorschlag zu Art. 62 Abs. 1 und 2; Bündnis für Direkte Demokratie, Direkte Demokratie in Berlin. So soll es sein! http://www.du-entscheidest-mit.de/806.99.html (Zugriff 8.9.2006), auch in: md magazin. zfdd 17 (2006), H. 4 (Nr. 72), S. 25.

18 Jung, Dreimal Fehlschlag (Fn. 13), S. 39. - Die gleiche Einschätzung galt vor der entsprechenden Reform für Thüringen wegen der gleichen Disproportion: Es sei ,,auf Grund 
bisherige Staatspraxis bestätigt dies, wenn seit 1995 acht Volksbegehren, aber nur eine einzige Einwohnerinitiative gestartet wurden ${ }^{19}$. Weixners genereller empirischer Befund, wenn die Möglichkeit zu Volksinitiativen bestehe, komme es „sehr viel weniger zu Volksbegehren“20, wird durch die Berliner Zahlen freilich nicht widerlegt; er gilt allerdings offenbar nur unter der Voraussetzung einer angemessenen Erschwernisstufung der verschiedenen Verfahren. Die Reform hat nun beide Hürden auf je 20.000 Unterschriften (allerdings bei verschieden weiten Kreisen der Berechtigten) gesenkt. Damit ist jener Fehlanreiz im wesentlichen entfallen ${ }^{21}$. Es bleibt freilich der oben genannte Kern des Problems: die isolierte Ausgestaltung der Einwohnerinitiative, d. h. wer immer gegen eine repräsentativ-demokratische Entscheidung direktdemokratisch angehen will, wird sich taktisch fragen, ob er erst 20.000 Unterschriften für eine Einwohnerinitiative sammeln soll, die gegebenenfalls - wenn die Auseinandersetzung weitergeht „verloren“ sind (das ist der Grundfehler), oder ob er nicht lieber mit dem gleichen Aufwand sofort die Eröffnung eines Volksgesetzgebungsverfahrens beantragt.

\subsubsection{Die Erleichterung des Grundverfahrens der Volksgesetzgebung}

Unter „Grundverfahren“ soll hier das direktdemokratische Regelwerk für einen einfachgesetzlichen Entwurf verstanden werden, also keine Verfassungsänderung, kein Volksbegehren zur vorzeitigen Beendigung der Wahlperiode des Abgeordnetenhauses, keine sogenannte ,andere Vorlage“, und auch die Tabuproblematik sei vorerst ausgespart. Dieses Grundverfahren wird künftig bereits

des sehr hohen Quorums für den Bürgerantrag (= Volksinitiative) sogar fest damit zu rechnen, daß die Initiatoren eine Gesetzesvorlage gleich durch ein Volksbegehren einbringen werden“, so T. Franke-Polz, Direkte Demokratie, hrsg. von der Landeszentrale für politische Bildung Thüringen, Erfurt 2003, S. 39. Ebenso für Berlin und Thüringen Weixner, Demokratie (Fn. 15), S. 157.

19 Siehe die Übersicht über die bislang unternommenen neun Anläufe für Volksinitiativen bzw. Volksbegehren in Berlin mit Angaben zu Ziel, Trägern und Verlauf sowie Links unter http://www.du-entscheidest-mit.de/802.99.html (Zugriff 12.8.2006). - Daß diese Volksbegehren alle nicht zustande kamen (darauf ist noch einzugehen), steht auf einem anderen Blatt. Aber die Entscheidung der Initiatoren, gleich ein Volksbegehren zu beantragen und nicht erst eine Einwohnerinitiative zu starten, hängt mit jenem Fehlanreiz zusammen.

20 Weixner, Demokratie (Fn. 15), S. 221.

21 Anders sehen dies M. Efler/C. Posselt, Direkte Demokratie in Berlin, in: H.K. Heußner/O. Jung (Hrsg.), Mehr direkte Demokratie wagen. Volksentscheid und Bürgerentscheid: Geschichte - Praxis - Vorschläge, 2. Aufl. München 2009, S. 285-304, für die bereits die gleiche Unterschriftenzahl das Instrument der Volksinitiative faktisch „entwertet" (304). 
dadurch erleichtert, daß die Zahl der für einen Zulassungsantrag geforderten Unterstützungsunterschriften, wie erwähnt, von 25.000 auf 20.000 gesenkt wird.

Ungleich wichtiger aber ist die Absenkung der Qualifizierungshürde beim Volksbegehren von bislang zehn (Art. 62 Abs. 4 VvB a.F.) auf künftig sieben Prozent (Art. 63 Abs. 1 S. 2 VvB n.F.). Die PDS hatte hier ursprünglich (2000) fünf Prozent, die Grünen (2005) hatten sechs Prozent gefordert, und das Bündnis für Direkte Demokratie (2006) wollte die Latte auf 100.000 Unterschriften gleich etwa 4,2 Prozent legen. Die Reformkoalition des Abgeordnetenhauses tastete sich, wie erwähnt, in kleinen Schritten an den Wert von sieben Prozent heran. Warum gerade dieser und kein anderer Wert schließlich konsensfähig war, ist völlig unklar ${ }^{22}$.

Diese Hürdensenkung bedeutet eine erhebliche Erleichterung, die voll anzuerkennen ist. Im Vergleich gilt es freilich festzuhalten, daß die zehn Prozent des bisherigen Rechts den klassischen deutschen - hohen - Wert schon der Weimarer Reichsverfassung (Art. 73 Abs. 3 S. 1) darstellten. Gewiß, der Verfassungsgeber hat 1995 nicht auf die prohibitiv hohe 20-Prozent-Hürde der Berliner Verfassung von 1950 (Art. 49 Abs. 1 S. 5) zurückgegriffen; aber auch jene zehn Prozent zeugten 1995 von großer Vorsicht, nachdem Schleswig-Holstein 1989 die Hürde auf fünf Prozent (ursprünglich Art. 42 Abs. 1 S. 3) - das war damals eine echte Innovation - und Brandenburg 1992 auf umgerechnet knapp vier Prozent (Art. 77 Abs. 3 S. 1) zu senken gewagt hatten. Daß die politische Elite Berlins nun 2006 drei Prozentpunkte nachzulassen sich getraute, ist auch vor dem Hintergrund zu relativieren, daß Hamburg bei seiner Reform 2001 den schleswig-holsteinischen Wert von fünf Prozent übernommen hat (Art. 50 Abs. 2 S. 3) und Nordrhein-Westfalen (2002) sowie Thüringen (2003) die Hürde auf acht Prozent gelegt haben (Art. 68 Abs. 1 S. 7 Verf. NRW bzw. Art. 82 Abs. 5 S. 2 ThürVerf. ${ }^{23}$ ). Berlin nahm nach dieser Reform also einen der vorderen Plätze, aber keineswegs die Spitze $\operatorname{ein}^{24}$. Eine Sieben-Prozent-Hürde mag man loben, wenn man an Hessen und das Saarland denkt, die für das Zustandekommen eines Volksbegehrens immer noch die Eintragung von 20 Prozent der Stimmberechtig-

22 Es verstößt gegen Buchstaben und Geist der Regeln des Parlamentarismus - was natürlich im Fall einer (Ad-hoc-)Allparteien-Koalition niemand rügt -, wenn in der „Begründung“ eines Gesetzentwurfs die vorgesehene Neuregelung lediglich paraphrasiert wird; von „Gründen“ ist gar keine Rede, so in Drs. 15/5038 v. 26.4.2006, S. 7 (Begründung zu Art. I Nr. 8 [zu Art. 63 Abs. 1]).

23 Hier gilt noch die Zusatzbedingung, daß sich die Initiatoren für die Amtseintragung entschieden haben müssen.

24 Vgl. die Übersicht über ,Das Verfahren für Volksbegehren und Volksentscheid in den 16 Bundesländern“ bei A. Kost (Hrsg.), Direkte Demokratie in den deutschen Ländern. Eine Einführung, Wiesbaden 2005, S. 368 f. Der Stand der Regelungen per Ende 2011 ist wiedergegeben bei F. Rehmet, Volksbegehrensbericht 2011 von Mehr Demokratie e.V., Berlin 2012, S. 10 . 
ten fordern. Man sollte aber nicht ignorieren, daß in den Direkte-Demokratieerprobten schweizerischen Kantonen und US-Bundesstaaten die entsprechende Hürde nur bei ein bis vier bzw. zwei bis vier Prozent liegt ${ }^{25}$.

Was läßt sich aus der bisherigen Staatspraxis zu dem alten bzw. dem neuen Regelwerk schließen? Daß die alte Hürde von zehn Prozent (bei nur zwei Monaten Zeit und Amtseintragung) „kaum zu überwinden“ sei - so Mehr Demokra$\mathrm{tie}^{26}$-, hat sie jedenfalls nicht gezeigt. Eine Aufgliederung der Gründe, woran die bisherigen Versuche scheiterten ${ }^{27}$, ergibt: Von acht Vorhaben insgesamt reichte die Unterstützung bei der Hälfte nicht einmal für den Zulassungsantrag ${ }^{28}$. Die anderen vier Projekte erhielten zwar genügend Unterstützung (25.000 Unterschriften nach altem Recht). Dann scheiterten aber zwei, bestätigt durch Urteile des Verfassungsgerichtshofs, an Ausschlußklauseln: das Volksbegehren „Mehr Demokratie in Berlin“ (1999) am Verfassungstabu ${ }^{29}$ und das Volksbegehren „Schluß mit dem Berliner Bankenskandal“ (2003/04) am Finanztabu. Ein Volksbegehren zur Parlamentsauflösung (,Neuwahlen Jetzt!“) erledigte sich, weil das Abgeordnetenhauses demnächst selbst beschloß, die Wahlperiode vorzeitig zu beenden. Mithin bleibt ein einziges Volksbegehren „Schluß mit der Rechtschreibreform“ (1999), das regulär durchgeführt wurde, aber mit 4,4 Prozent Eintragungen nicht die alte Zehn-Prozent-Hürde überwand ${ }^{30}$. Für die neue Hürde von sieben Prozent hätte die damals mobilisierte bzw. mobilisierbare Unterstützung freilich auch nicht gereicht ${ }^{31}$. Aus diesem einen Fall aber läßt sich keine generelle Aussage wie die oben zitierte ableiten.

$\mathrm{Zu}$ der nunmehr gesenkten Qualifizierungshürde hat sich der Fachverband Mehr Demokratie durchaus zuversichtlich geäußert. Erst hieß es diplomatisch,

Vgl. H.K. Heußner, Mehr als ein Jahrhundert Volksgesetzgebung in den USA, in: Heußner/Jung, Demokratie (Fn. 21), S. 135-156 (136 f.); W. Linder, Schweizerische Demokratie. Institutionen - Prozesse - Perspektiven, 2. Aufl. Bern/Stuttgart/Wien 2005, S. 271.

26 Vgl. die Kritik der bisherigen Situation unter http://www.du-entscheidest-mit.de/803. 99.html (Zugriff 12.8.2006).

27 Das Folgende nach der Übersicht über die bislang unternommenen neun Anläufe für Volksinitiativen bzw. Volksbegehren in Berlin mit Angaben zu Ziel, Trägern und Verlauf sowie Links unter http://www.du-entscheidest-mit.de/802.99.html (Zugriff 12.8.2006). Vgl. Efler/Posselt, Demokratie (Fn. 21), S. 288 ff.

28 Es waren dies die Volksbegehren „Schluß mit den Kürzungen im Kita-Bereich“ (2003/04), „Sicherstellung von Kita-, Schul- und Hochschulstudienplätzen“ (2003/04), „Neuwahlen“ (2004) und „Soziales Berlin“ (2004). - Ob die Initiatoren die Eignung ihrer Anliegen für ein massendemokratisches Verfahren überschätzten oder die Mühe und den Aufwand für ein Volksgesetzgebungsverfahren unterschätzten, kann hier dahinstehen.

29 Vgl. Jung, Dreimal Fehlschlag (Fn. 13), S. 39-45.

30 Vgl. a.a.O., S. 45-56, Zahlen nach S. 50.

31 Solche Aussagen stehen freilich immer unter einem methodologischen Vorbehalt. Ihre grundlegende Bedingung des „ceteris paribus“ ist gerade nicht gegeben, wenn statt des Abschreckungseffekts des alten Regelwerks neue, günstigere Bedingungen Hoffnungen auf Erfolg wecken. 
diese Senkung „hätte deutlicher ausfallen können“. Aber dann verlagerte man interessant den Schwerpunkt und erklärte es für „,entscheidend“, daß bei der anstehenden Anpassung des Ausführungsgesetzes „die Pflicht zur Amtseintragung abgeschafft und die freie Sammlung der Unterschriften zugelassen wird, damit Volksbegehren eine reelle Chance bekommen “32. Bei den drei nach der Reform vollständig durchgeführten Volksgesetzgebungsverfahren („Flughafen Tempelhof", „Pro Reli“ und „Offenlegung der Wasserverträge“) jedenfalls zeigte sich, daß - unabhängig vom Eintragungsverfahren - die neue Volksbegehrenshürde problemlos genommen wurde. Die Sieben-Prozent-Hürde wirkt offenbar, wie vorgesehen, als Relevanzfilter, behindert aber wichtige Anliegen nicht ernsthaft ${ }^{33}$.

Am Schluß des Verfahrens - beim Volksentscheid - ersetzte die Reform die bislang geltende alternative „Berliner Doppelhürde“ - bei 50 Prozent Beteiligung genügte die einfache Mehrheit, bei geringerer Beteiligung war die Zustimmung von 33 Prozent der Stimmberechtigten erforderlich (Art. 63 Abs. 2 VvB a.F.) durch ein einheitliches, beteiligungsunabhängiges Zustimmungsquorum von 25 Prozent (Art. 63 Abs. 1 S. 3 VvB n.F.). Die PDS (2000) und die Grünen (2005), die - ebenso wie das Bündnis (2006) - übereinstimmend die erzdemokratische Regel gefordert hatten, daß die Mehrheit der abgegebenen (gültigen) Stimmen entscheiden solle - also den quorenlosen Volksentscheid -, vermochten sich in den Verhandlungen der interfraktionellen Arbeitsgruppe offenbar nicht durchzusetzen. Diese Reform hat das Quoren-Regelwerk nicht nur „deutlich vereinfacht“, wie die offizielle Begründung hervorhob ${ }^{34}$, sondern vor allem den Volksentscheid bedeutend erleichtert. Dazu muß man sich klarmachen, daß jenes Alternativquorum - übrigens eine Berlinensie ${ }^{35}$ - faktisch ein Zustimmungsquorum von 33 Prozent bedeutete; die Alternative: 25 Prozent bei Beteiligung der Hälfte

32 Berlin wird demokratischer (Fn. 12). - Auch der PDS war 2000 - neben den hohen Quoren und der kurzen Eintragungsfrist - die ausschließliche Amtseintragung als ,ein entscheidender Grund“ dafür erschienen, ,daß erfolgreiche Volksbegehren derzeit nahezu unmöglich“ seien, Drs. 14/655 v. 14.9.2000, S. 3 (Begründung zu Art. 62 Abs. 3).

C. Pestalozza, Auf gutem Weg: Direkte Demokratie in Berlin, in: JdD 1 (2009), S. 295316, erscheinen Quorum und Frist beim Volksbegehren ,fair“ (312) - mangels Begründung und Vergleich freilich eher ein ,gefühltes“ Urteil.

34 Drs. 15/5038 v. 26.4.2006, S. 7 (Begründung zu Art. I Nr. 8 [zu Art. 63 Abs. 1]).

35 Vgl. schon Art. 49 Abs. 4 VvB 1950. Zur Entstehungsgeschichte siehe O. Jung, Grundgesetz und Volksentscheid. Gründe und Reichweite der Entscheidungen des Parlamentarischen Rats gegen Formen direkter Demokratie, Opladen 1994, S. 135 f., 138 f. - Ferner die gute kritische Darstellung bei F. Meerkamp, Die Quorenfrage im Volksgesetzgebungsverfahren. Bedeutung und Entwicklung, Wiesbaden 2011 (Bürgergesellschaft und Demokratie Bd. 36), S. 487 f., mit zutreffender Kritik an der überkommenen Begriffsbildung, a.a.O., S. 486 Fn. 2452. 
der Stimmberechtigten, war reine Theorie ${ }^{36}$. Parteien sind ja nicht passive $\mathrm{Zu}$ schauer des Abstimmungsgeschehens, die abwarten, wie wohl die Beteiligung und die Zustimmung ausfallen werden, um dann das nach der Verfassung maßgebliche Quorum anzuwenden. Parteien sind vielmehr machtorientierte Akteure, wollen ihre politischen Ziele durchsetzen und gehen dabei selbstverständlich auch taktisch vor. Die Abstimmungsbeteiligung ist daher für Parteistrategen keine von außen kommende, unbeeinflußbare Größe, die einfach hinzunehmen wäre, sondern sie stellt eine für politische Einwirkung durchaus offene Variable dar, für die folgendes Kalkül gilt: Eine hohe Beteiligung birgt für die Sachgegner die „Gefahr“, daß eine an den Urnen mehrheitlich angenommene Vorlage mit einer Zustimmung von 26 Prozent der Stimmberechtigten ,durchkommt“. Daher werden sie alles tun, um die Abstimmungsbeteiligung niedrig zu halten - vom Totschweigen bis zum Boykottaufruf -, damit die Zustimmungshürde auf 33 Prozent steigt und sie so den volksbegehrten Entwurf doch noch ,abfangen“ können $^{37}$.

Das bisherige 33prozentige Zustimmungsquorum war die zweithöchste einschlägige Hürde in Deutschland, übertroffen nur noch von dem absurden 50Prozent-Zustimmungsquorum im Saarland (Art. 100 Abs. 3) ${ }^{38}$, geteilt im übrigen

36 Ein Beispiel solcher (schlechter) Theorie ist Borcherts Plädoyer noch 1999 für ein ,kompensatorisches Quorum“, das es ermögliche, ,eine niedrigere Beteiligung durch eine höhere Zustimmung auszugleichen. Auf diese Weise würde die strategische Stimmenthaltung sehr viel riskanter. So könnte ein gezielter institutioneller Anreiz geschaffen werden, sich an der Abstimmung zu beteiligen - und auch die vorausgehende öffentliche Diskussion mit dem gebotenen Ernst zu bestreiten.“ E. Borchert, Politische Klasse ohne demokratische Kontrolle? Die Pathologien der politischen Professionalisierung und die Zukunft der Demokratie, in: H.H. v. Arnim (Hrsg.), Direkte Demokratie. Beiträge auf dem 3. Speyerer Demokratieforum vom 27. bis 29. Oktober 1999 an der Deutschen Hochschule für Verwaltungswissenschaften Speyer, Berlin 2000 (Schriftenreihe der Hochschule Speyer Bd. 140), S. 113-135 (133). Nun hatte Borchert nicht das Regelwerk für die Berliner Volksgesetzgebung, sondern für das abrogative Referendum in Italien vor Augen, und in der Tat wären dort etliche durch systematischen Boykott hintertriebene Projekte (vgl. A. Capretti, Öffnung der Machtstrukturen durch Referenden in Italien. Eine pluralismustheoretische Analyse, Frankfurt a.M./Berlin 2001 [Interdisziplinäre EuropaStudien Bd. 2], S. 98-100) bei einem solchen „kompensatorischen Quorum“ durchgekommen. Aber die alternative „Berliner Doppelhürde“ hätte in der Praxis, wie gleich ausgeführt wird, in die umgekehrte Richtung funktioniert. - Siehe jedoch den kreativen Vorschlag eines „,anti-proportionalen Beteiligungsquorums“ von T. Hüller, Herrschaft des Quorums? Ein Vorschlag zur Lösung eines Problems direkter Demokratie, in: ZParl 37 (2006), S. 823-833.

37 Vgl. O. Jung, Zur Problematik des Beteiligungsquorums, in: JdD 1 (2009), S. 40-65 (53 f.).

38 Vgl. G. Jürgens, Die anderen Bundesländer, in: H.K. Heußner/O. Jung (Hrsg.), Mehr direkte Demokratie wagen. Volksbegehren und Volksentscheid: Geschichte - Praxis Vorschläge, 1. Aufl. München 1999, S. 223-236 (231): „völlig illusorisch“; Weixner, Demokratie (Fn. 15), S. 162: „völlig unerreichbar“. Ferner O. Jung, Die Reform der di- 
von Baden-Württemberg (Art. 60 Abs. 5 S. 2) und Mecklenburg-Vorpommern (Art. 60 Abs. 4 S. 1). Nach der Reform befindet sich Berlin in der Gesellschaft von Brandenburg (Art. 78 Abs. 2) - darauf wies auch die Begründung hin ${ }^{39}$ und vier weiterer Länder ${ }^{40}$. Aber zur Einschätzung des Erreichten sei daran erinnert, daß es auch anders geht. In Hamburg genügt seit der Reform von 2001 ein Zustimmungsquorum von 20 Prozent (Art. 50 Abs. 3 S. 4) - ebenso inzwischen in Bremen seit 2009 (Art. 72 Abs. 1) ${ }^{41}$-, Nordrhein-Westfalen führte 2002 ein Zustimmungsquorum von 15 Prozent ein (Art. 68 Abs. 4 S. 2), und Bayern, Hessen und Sachsen verfahren weiterhin nach dem urdemokratischen Prinzip, daß allein die Mehrheit der abgegebenen (gültigen) Stimmen entscheidet (Art. 2 Abs. 2 S. 2 BayVerf., Art. 124 Abs. 3 S. 2 HessVerf., Art. 72 Abs. 4 S. 2 SächsVerf.), ohne irgendwelche Quoren - und jeweils ohne daß sich Unzuträglichkeiten gezeigt hätten.

Die Senkung des Zustimmungsquorums von 33 auf 25 Prozent hat den Volksentscheid, wie gesagt, bedeutend erleichtert; aber hat sie ihn auch genügend leicht gemacht? Bei der I. Lesung im Abgeordnetenhaus meinte der Unterhändler der FDP unverblümt, diese 600.000 Ja-Stimmen seien „,eine Hürde, die fast astronomisch ist", und malte farbig aus, was fachlich ,symbolische Politik“ heißt: „Wir müssen dabei aufpassen, daß die Bürger nicht den Eindruck bekommen, daß wir sie veräppeln wollen und nur simulieren, wir würden direkte Demokratie einführen, aber dann die Hürde so hoch setzen, daß es nicht zu reißen ist." ${ }^{\text {*42 }}$ Der Fachverband Mehr Demokratie sagte voraus, daß „die meisten Volksentscheide“ auch an der neuen Hürde scheitern würden ${ }^{43}$. Die Änderungen stellten zwar ,eine leichte Verbesserung“ dar, würden die Volksgesetzgebung aber ,weiterhin stark behindern“. Von den Volksbegehren, die bisher in den Bundesländern stattfanden, „hätten nur drei diese hohen Hürden überwunden““44. Dazu legte Mehr De-

rekten Demokratie im Saarland - Teil I: Problemlage und Grundfragen, in: LKRZ 2 (2008), S. 41-46 (45).

39 Drs. 15/5038 v. 26.4.2006, S. 7 (Begründung zu Art. I Nr. 8 [zu Art. 63 Abs. 1]).

40 Es sind dies Niedersachsen (Art. 49 Abs. 2 S. 1), Sachsen-Anhalt (Art. 81 Abs. 3 S. 2), Schleswig-Holstein (Art. 42 Abs. 4 S. 1) und - seit der Reform 2003 - Thüringen (Art. 82 Abs. 7 S. 3).

41 Vgl. D. Schefold, Die Neuregelung des Volksentscheids in Bremen vom 1. September 2009, in: JdD 2 (2010), S. 135-154 (148).

42 Abg. Alexander Ritzmann (FDP), AH 4.5.2006, S. 7347 D. - Das letzte Bild war schief. Gemeint war: „,... die Hürde so hoch setzen, daß sie nicht zu überwinden ist, sondern immer gerissen wird.“

Vgl. Mehr Demokratie e.V.: Du entscheidest mit! Die Reform, http://www.du-entscheidest-mit.de/804.99.html (Zugriff 12.8.2006).

Siehe Berlin wird demokratischer (Fn. 12). 
mokratie eine Übersicht vor: „Was wäre, wenn ... die bisherigen Volksentscheide in Deutschland nach dem geplanten Berliner Recht erfolgt wären?“45

Jene Prognose traf per 2006 zu. Der empirische Beleg: In Deutschland war bis dahin für den Normalfall mit einer Beteiligung an Volksentscheiden über ,von unten" initiierte, einfachgesetzliche Vorlagen zwischen 25,9 Prozent (in Sachsen 2001: „Sparkassenorganisation“) und 43,8 Prozent (Bayern 1991: „Abfallwirtschaftsgesetz") zu rechnen, und die Zustimmung bei volksbegehrten einfachgesetzlichen Entwürfen lag zwischen 15,9 Prozent (Sachsen-Anhalt 2005: „Kinderbetreuung“) und 22,0 Prozent der Stimmberechtigten (Sachsen 2001: „Sparkassenorganisation“ $)^{46}$. Die Volksentscheide, die seitdem stattfanden -2010 in

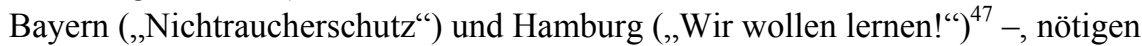
zu keiner Korrektur: Dank des bayerischen Falls stieg das Zustimmungsmaximum auf 22,9 Prozent.

Akzeptiert man die direktdemokratische Partizipation, wie sie die fünf Bundesländer Bayern, Schleswig-Holstein, Hamburg, Sachsen und Sachsen-Anhalt (aus denen allein Daten vorliegen) bislang kennen, dürfte man für einfachgesetzliche Entwürfe ein Quorum von höchstens 15 Prozent (wie in NordrheinWestfalen) ansetzen, um derlei Vorhaben eine Chance zu geben ${ }^{48}$. So schrumpft die bedeutende Erleichterung nach dem Verfassungstext in der Wirklichkeit direktdemokratischer Partizipationschancen doch erheblich: War eine erfolgreiche Volksgesetzgebung in Berlin bislang ziemlich ausgeschlossen, erscheint sie weiterhin nur unter besonders günstigen Umständen vorstellbar ${ }^{49}$.

45 http://www.du-entscheidest-mit.de/fileadmin/berlin/pdf/was_waere_wenn.pdf (Zugriff 10.9.2006). - Dabei wurden 13 Volksentscheide zugrunde gelegt, allerdings Fälle, in denen über einfache Gesetzentwürfe abgestimmt wurde - die jetzt hier interessieren -, und Fälle verfassungsändernder Gesetzentwürfe - auf die noch einzugehen ist - zusammengenommen.

46 Vgl. O. Jung, Volksentscheide in den deutschen Bundesländern von 1945-2008, in: Heußner/Jung, Mehr direkte Demokratie (Fn. 21), S. 225-233. - Die darüber liegenden Beteiligungs- und Zustimmungswerte in Schleswig-Holstein 1998 („Rechtschreibreform“) und Hamburg 1998 (,Bezirklicher Bürgerentscheid“) bzw. 2004 (,Krankenhausprivatisierung“) sind statistische „Ausreißer“: Hier spielte offenbar der „HuckepackEffekt“ eine Rolle, daß jene Volksentscheide auf den Tag der Bundestagswahl (1998) bzw. der Bürgerschaftswahl (2004) gelegt worden waren.

47 Vgl. JdD 2 (2010), S. 156 f. und eigene Berechnung.

48 So schon Jung, Thüringen (Fn. 9), S. 276.

49 Weixner (Demokratie [Fn. 15], S. 163) hat das Erfordernis von 25 Prozent Zustimmung geradezu gefeiert als ein „gemäßigtes Quorum“ und es „durchaus für sinnvoll“ erachtet; es sei ,erreichbar, stärkt die gesellschaftliche Akzeptanz einer plebiszitären Entscheidung und ermutigt zu weiteren Volksinitiativen“. Indes sind diese Urteile ohne empirisches Fundament gefällt, d.h. Weixner hat - entgegen ihrem eigenen Anspruch - keine Daten über die in den Bundesländern bislang praktisch erreichten Beteiligungs- und Zustimmungswerte erhoben. 
Dies bestätigt der Ausfall der drei unter dem neuen Regelwerk abgehaltenen Volksentscheide, deren Zahl in rascher Folge ja zunächst imposant wirkt: Der Volksentscheid zum Flughafen Tempelhof scheiterte 2008 „unecht“ an jenem 25prozentigen Zustimmungsquorum ${ }^{50}$. Beim Volksentscheid „Pro Reli“ (2009) kam es auf jenes Zustimmungsquorum rechtlich gar nicht an, weil die Vorlage an den Urnen mehrheitlich abgelehnt wurde; rein rechnerisch hätten aber auch hier weder die Befürworter noch die siegreichen Gegner jene 25 Prozent Zustimmung erreicht $^{51}$. Beim Volksentscheid 2011 über die „Offenlegung der Wasserverträge“ ergab sich zwar eine Ja-Mehrheit an den Urnen, die zugleich das 25-ProzentZustimmungsquorum überwand, womit das erste Volksgesetz in Berlin zustande kam. Aber die Zahlen belegen den Ausnahmefall der Situation: Beteiligung 27,5 Prozent, davon votierten mit „Ja“ 98,3 (!) Prozent, somit stimmten 27,0 Prozent der Stimmberechtigten $\mathrm{zu}$ - die etablierte Politik war einfach nicht ,angetreten ${ }^{\text {“52. }}$.

Übrigens ist auch hier wegen der Intransparenz des Entscheidungsprozesses unklar, wie die Reformer zu dem 25prozentigen Zustimmungsquorum kamen. Es ist leider anzunehmen, daß man Beteiligungswerte, wie sie bei Wahlen üblich sind, einfach auf Volksabstimmungen übertrug und die empirischen Untersuchungen, die das als eine überzogene Partizipationserwartung erweisen, ignorier$\mathrm{te}^{53}$.

\subsubsection{Die Einführung der verfassungsändernden Volksgesetzgebung}

Mit dem Ausschluß der verfassungsändernden Volksgesetzgebung war die revidierte Berliner Verfassung von 1995 „einsame Spitze“. Alle anderen Landesverfassungen mochten das Verfahren erschweren oder verbauen bzw. gar wie das

50 Vgl. Efler/Posselt, Demokratie (Fn. 21), S. 291. - Erreicht wurden nur 21,7 Prozent der Stimmberechtigten.

51 Vgl. O. Jung, Direkte Demokratie in Berlin. Der Fall „Pro Reli“ 2007-2009, Berlin 2011, S. 141, 143 f. - Rechnerisch erzielten die ersteren 14,1 und die letzteren 15,0 Prozent.

Vgl. JdD 3 (2011), S. 133 f.; O. Jung, Ein neuer Modus der direkten Demokratie? Der Volksentscheid über die Offenlegung der Teilprivatisierungsverträge bei den Berliner Wasserbetrieben am 13. Februar 2011, in: md magazin. zfdd 23 (2011), H. 1 [Nr. 88], S. 4-10 (9).

53 Problematisch ist auch Pestalozzas Vorgehen, dem das 25-Prozent-Zustimmungsquorum „nicht unfair“ erscheint, wenn er es mit den Voraussetzungen der Beschlußfähigkeit des Abgeordnetenhauses nach Art. 43 Abs. 1 VvB (Anwesenheit von mehr als der Hälfte der Abgeordneten) vergleicht (ders., Auf gutem Weg [Fn. 33], S. 312 f.). Zu hinterfragen wäre doch, ob ein Vergleich der Regeln für eine (kleine, professionelle) Volksvertretung mit den Anforderungen an einen demokratischen Urakt wie Volksabstimmungen (und auch Wahlen!) überhaupt angemessen ist. 
Saarland es imperfekt gestalten, also einen Volksentscheid über ein auf Änderung der Verfassung gerichtetes Volksbegehren ausschließen (Art. 100 Abs. 4 SaarlVerf.). Aber die Verfassungsänderung zu tabuisieren - jene Materie, mit der historisch gesehen die Geschichte der direkten Demokratie begann und die sich viel besser für Volksabstimmungen eignet als die oft kleinteilige einfache Gesetzgebung $^{54}$-, war einfach ein skandalon ${ }^{55}$. Die CDU, die 1995 - damals stärkste Fraktion und Regierungspartei - dieses Tabu durchgesetzt hatte ${ }^{56}$, mußte sich nun - mit Mühe noch zweitstärkste Fraktion vor der nachdrängenden Linkspartei.PDS und in der Opposition - schon einen Ruck geben, um diese von ihr mangels Sperrminorität ja nicht mehr zu verhindernde Reform nun trotz der Einführung der perhorreszierten verfassungsändernden Volksgesetzgebung sogar zu unterstützen. Die PDS hatte schon 2000 für die Einführung der verfassungsändernden Volksgesetzgebung plädiert. Die Grünen, die in ihrem eigenen Entwurf 2005 das Verfassungstabu noch unangetastet gelassen hatten ${ }^{57}$, sprangen jetzt natürlich gerne auf den Zug auf, als sich die Gelegenheit bot.

Ob das Bündnis mit seinem Vorschlag, für verfassungsändernde Entwürfe die Hürde beim Volksbegehren zu verdoppeln, einen entscheidenden Anstoß für die Interfraktionelle Arbeitsgruppe gegeben hat, muß offenbleiben. Jedenfalls verständigte sich diese bald darauf, daß für solche Entwürfe sich 20 Prozent der Stimmberechtigten sollten eintragen müssen (siehe schließlich Art. 63 Abs. 2 S. $2 \mathrm{VvB}$ n.F.); man orientierte sich dabei an den geltenden Regelungen für die plebiszitäre Parlamentsauflösung (Art. 63 Abs. 3 S. 1 VvB a.F. $\left.{ }^{58}\right)^{59}$. Das Prinzip des Splittings ist aus den schweizerischen Kantonen und den US-Bundesstaaten bekannt $^{60}$. Für eine solche Differenzierung spricht die praktische Vernunft: Es erscheint sinnvoll, das Besondere der verfassungsändernden Volksgesetzgebung gegenüber dem Grundverfahren der (einfachgesetzlichen) Volksgesetzgebung nicht erst am Schluß, sondern bereits am Anfang des Verfahrens durch spezielle Anforderungen auszudrücken. Im geltenden deutschen Landesverfassungsrecht ${ }^{61}$ hat allerdings erst Bremen bei der Verfassungsrevision 1994 ein solches Splitting eingeführt: Die bisher einheitliche Volksbegehrenshürde von 20 Prozent wurde für einfachgesetzliche Vorhaben auf zehn Prozent gesenkt, aber für verfassungs-

54 Vgl. O. Jung, Grundsatzfragen der direkten Demokratie, in: Kost, Direkte Demokratie (Fn. 24), S. 312-366 (316).

55 Vgl. Jung, Abschluß (Fn. 5), S. 64. - Pestalozza, Auf gutem Weg (Fn. 33), S. 315, nannte die damalige Entscheidung, geradezu anachronistisch“.

56 Vgl. Jung, a.a.O., S. $61 \mathrm{f}$.

57 Vgl. Drs. 15/4472 v. 16.11.2005, Art. I Nr. 2 d (zu Art. 62 Abs. 6).

58 Art. 63 Abs. 3 S. 2 VvB n.F.

59 Vgl. Drs. 15/5038 v. 26.4.2006, S. 7 (Begründung zu Art. I Nr. 8 [zu Art. 63 Abs. 2]).

60 Vgl. Linder, Demokratie (Fn. 25), S. 271; Heußner, Jahrhundert (Fn. 25), S. 136 f.

61 Zur Weimarer Zeit sah z.B. $§ 10$ Abs. 2 S. 2 der Verfassungsurkunde des Freistaates Bayern von 1919 eine solche Erschwernisstufung vor (zehn bzw. 20 Prozent). 
ändernde Entwürfe beibehalten ${ }^{62}$. Der nähere Blick auf die Referenzländer zeigt freilich die Problematik des nun für Berlin beschlossenen Regelwerks: In den schweizerischen Kantonen und den US-Bundesstaaten wurden die Hürden für verfassungsändernde Vorhaben moderat erhöht ${ }^{63}$ und maximal verdoppelt; Bremen verdoppelte - systematisch gesehen. Demgegenüber haben die Reformer in Berlin die Hürde für das besondere Verfahren der Verfassungsänderung fast verdreifacht: statt sieben sollen 20 Prozent einen solchen Entwurf unterstützen müssen. Daß auch die Unterschriftenzahl für den Zulassungsantrag bei einer geplanten Verfassungsänderung nicht verdoppelt, sondern von 20.000 auf 50.000, d.h. auf das Zweieinhalbfache, gesteigert wurde (Art. 63 Abs. 1 S. 1, Abs. 2 S. 1 VvB n.F.), wundert da schon nicht mehr. Ob dieses Problem der Fehl-Proportion der beiden Volksbegehrenshürden von den Reformern überhaupt gesehen wurde, ist nicht bekannt.

Betrachtet man die 20-Prozent-Hürde isoliert, läßt sich über sie als einziges Positives sagen, daß damit an die Tradition der Berliner Verfassung von 1950 wieder angeknüpft wird, wo jedwede Volksgesetzgebung, die einfache wie die verfassungsändernde, eine solche hohe Qualifizierungshürde zu überwinden hatte (vgl. Art. 49 Abs. 1 S. 1 VvB 1950). Aber diese Wiederaufnahme erscheint nicht reflektiert. 60 Jahre (Nicht-)Praxis in den Bundesländern, die eine 20-Prozent-Hürde haben (heute noch Hessen und das Saarland) bzw. jahrzehntelang bis zu Verfassungsrevisionen - hatten (so Bremen, Nordrhein-Westfalen und Rheinland-Pfal $z^{64}$ ), zeigen, daß diese Hürde nahezu unüberwindlich ist. Nur ein einziges Mal, beim Koop-Volksbegehren in Nordrhein-Westfalen 1978 - freilich unter verschiedenen Gesichtspunkten ein Ausnahmefall -, als sich 29,8 Prozent der Stimmberechtigten eintrugen ${ }^{65}$, gelang es, diese Hürde zu nehmen. Will man, daß ein Volksbegehren auf Verfassungsänderung nur einmal in einem halben Jahrhundert zustande kommt, wie diese Daten lehren?

Vgl. Art. 70 Abs. 1 S. 1 d und S. 2 Verf.; vgl. H. Neumann, Die Verfassung der Freien Hansestadt Bremen. Kommentar, Stuttgart u.a. 1996, Art. 70 Rn. 10. - Bei der Reform der direkten Demokratie in Thüringen 2003 favorisierten die Oppositionsparteien ebenfalls ein Splitting-Modell, konnten sich aber nicht durchsetzen.

63 Z.B. in Luzern von 1,7 auf 2,2 Prozent und im Wallis von 2,2 auf 3,4 Prozent der Stimmberechtigten, vgl. Linder, Demokratie (Fn. 25), S. 271 (umgerechnet). Entsprechend z.B. in Kalifornien von 5 auf 8 Prozent und in Michigan von 8 auf 10 Prozent, aber jeweils nicht der Stimmberechtigten, sondern der Aktivbürgerschaft, vgl. Heußner, Jahrhundert (Fn. 25), S. 137 Erl. 1. Vgl. Jung, Grundsatzfragen (Fn. 54), S. 323 f. - Auch die Thüringer Opposition wollte die Hürde moderat (von 7 auf 10 Prozent) erhöhen, vgl. Jung, Thüringen (Fn. 9), S. 272.

65 Vgl. O. Jung, Daten zu Volksentscheiden in Deutschland auf Landesebene (1946-1992), in: ZParl 24 (1993), S. 5-13 (9). 
Für den Volksentscheid zum Abschluß des Verfahrens bestimmte die Reform, daß das verfassungsändernde Volksgesetz nur dann angenommen sei, wenn eine Zweidrittel-Mehrheit der Abstimmenden und zugleich die Hälfte der Stimmberechtigten zustimmten (Art. 63 Abs. 2 S. 3 VvB n.F.). Für diese interne Qualifizierung und das Quorum nahmen sich die Reformer bzw. ihre Mehrheit - hier: SPD und $\mathrm{CDU}^{66}$ - wieder die brandenburgische Verfassung (Art. 78 Abs. 3 S. 1) zum Vorbild ${ }^{67}$. Gegenüber der Verfassungsrechtslage, wie sie von 1950 bis 1974 bestand, bedeutete diese Hürde eine erhebliche Erschwerung: Seinerzeit wurde „nur“ ein 50prozentiges Zustimmungsquorum aufgestellt (Art. 88 Abs. 2 VvB 1950), aber nicht zusätzlich eine interne Qualifizierung verlangt. Zu fragen wäre doch - ob die Reformer dieses Problem überhaupt gesehen haben, ist unklar -, warum man im relativen äußeren und inneren Frieden des Jahres 2006 eine direktdemokratische Verfassungsänderung (noch) schwieriger machte, als es die politischen Vorväter und -mütter 1950 während des Kalten Krieges in einem gespaltenen Land für geboten gehalten hatten. Die schon zur Verfassungsgebung von 1995 aufgeworfene Frage, ob es mangels empirischer Erfahrungen wenigstens „,neue überzeugende Einsichten der Theorie“ gebe, „die es geraten erscheinen lassen, von der Konzeption von 1950 abzugehen “68, ist jedenfalls mit dem lapidaren Verweis auf die Regelungen des Nachbarlandes nicht beantwortet.

Mit der Wahl jener Schlußhürde entstand ein zweites Proportionsproblem: das Verhältnis zu den Anforderungen an einen Volksentscheid zur Parlamentsauflösung. Ursprünglich wollten die Reformer für beide Verfahren die gleichen Bedingungen aufstellen, wie es übrigens die meisten Bundesländer - darunter auch Brandenburg - tun, in denen eine plebiszitäre Parlamentsauflösung überhaupt möglich ist ${ }^{69}$. Damit standen die Verantwortlichen aber vor dem Dilemma, ent-

66 Linkspartei.PDS, Bündnis 90/Die Grünen und FDP dagegen hielten „die Mehrheit der abgegebenen Stimmen als Ausdruck des Volkswillens für ausreichend“", vgl. den Kurzbericht über das öffentliche Hearing „Wie viel Demokratie wollen wir wagen?“ am 27.3.2006, http://www.du-entscheidest-mit.de/uploads/media/Kurzbericht.pdf (Zugriff 31.10.2006). - 2000 hatte die PDS noch vorgeschlagen, für verfassungsändernde Gesetzentwürfe die „Berliner Doppelhürde“ - also faktisch ein Zustimmungsquorum von 33 Prozent - weitergelten zu lassen, Drs. 14/655 v. 14.9.2000, S. 2 (Art. I Nr. 4 [zu Art. 63 Abs. 4]).

67 Vgl. Drs. 15/5038 v. 26.4.2006, S. 7 (Begründung zu Art. I Nr. 8 [zu Art. 63 Abs. 2]).

68 Jung, Abschluß (Fn. 5), S. 65.

69 Von den fünf anderen Bundesländern, in denen das Parlament durch Volksentscheid aufgelöst werden kann, schalten drei die Anforderungen zu denen einer direktdemokratischen Verfassungsänderung parallel (vgl. Art. 43 Abs. 2, 64 Abs. 3 S. 3 Bad-Württ. Verf., Art. 78 Abs. 3 S. 1 BbgVerf., Art. 72 Abs. 2, 76 Abs. 2 BremVerf.). Eigentlich gehört auch Bayern zu dieser Gruppe, dessen Verfassung in beiden Verfahren einen quorenlosen Volksentscheid vorsah. Hier hat die richterrechtliche Verfassungsänderung 1999, bei welcher der Verfassungsgerichtshof ein Zustimmungsquorum für die verfassungsändernde Volksgesetzgebung „,erfand“ (C. Pestalozza, Aus dem Bayerischen Verfassungs- 
weder die Anforderungen an die plebiszitäre Parlamentsauflösung deutlich heraufzusetzen (Nivellierung nach oben) oder auf die gewünschte, besonders hohe Schlußhürde bei der verfassungsändernden Volksgesetzgebung zu verzichten (Nivellierung nach unten) - oder aber jenes Prinzip der gleichen Anforderungen aufzugeben. Man entschied sich für letzteres. Für den Volksentscheid zur Auflösung des Abgeordnetenhauses blieb es bei dem 50prozentigen Beteiligungsquorum (Art. 63 Abs. 3 S. 3 VvB n.F. ${ }^{70}$ ). Diese Anforderung ist natürlich bedeutend geringer als jene für einen verfassungsändernden Volksentscheid, bzw. umgekehrt: Dieser ist deutlich anspruchsvoller als jener zur plebiszitären Parlamentsauflösung. Verfassungsgeschichtlich sei dazu angemerkt, daß auch schon die Berliner Verfassung von 1950 ein solches Anforderungsgefälle kannte ${ }^{71}$. Komparatistisch sei festgehalten, daß dieses Gefälle keine Berlinensie ist: Auch in Rheinland-Pfalz ist seit jeher ein verfassungsändernder Volksentscheid erheblich schwerer als die plebiszitäre Auflösung des Landtags ${ }^{72}$.

Die Art und Weise, wie das Verfahrens-,,Design“ der verfassungsändernden Volksgesetzgebung zustande kam, zeugt von wenig systematischem Sinn bei den Reformern. Einmal orientierte man sich an dem Brandenburger Vorbild, dann wieder nicht. $\mathrm{Da}$ das brandenburgische Regelwerk ein Typus ist, nämlich dem sogenannten „Kieler Modell“ der Volksgesetzgebung folgt, das nach 1989 in den fünf neuen Bundesländern sowie in Niedersachsen und Hamburg rezipiert wur$\mathrm{de}^{73}$, und daß bei diesem Modell beispielsweise trotz der sehr hohen Hürden beim abschließenden Volksentscheid der Verfahrensbeginn mit einer Volksbe-

leben 1989 bis 2002, in: JöR 51 [2003], S. 121-192 [127-130]) bzw. „erdachte“ (ders., Der Bayerische Landtag. Verfassung und Verfassungswirklichkeit, in: F. Kramer [Hrsg.], Der Landtag in der Bayerischen Verfassung von 1946, München 2009 [Beiträge zum Parlamentarismus Bd. 15], S. 25-57 [49 Fn. 37]), die Proportion außer acht gelassen.

70 Entspricht Art. 63 Abs. 3 S. 2 VvB a.F.

71 Für die verfassungsändernde Volksgesetzgebung galt ein 50prozentiges Zustimmungsquorum (Art. 88 Abs. 2 VvB 1950), für die plebiszitäre Parlamentsauflösung dagegen nur ein 50prozentiges Beteiligungsquorum (Art. 39 Abs. 1 S. 3 VvB 1950). - Auch der PDSEntwurf von 2000 wies ein solches Gefälle auf: Für die verfassungsändernde Volksgesetzgebung sollte die „Berliner Doppelhürde“ weitergelten, d.h. faktisch ein 33prozentiges Zustimmungsquorum, für einen Volksentscheid zur Auflösung des Abgeordnetenhauses war dagegen nur ein Zustimmungsquorum von 20 Prozent vorgesehen, Drs. 14/655 v. 14.9.2000, S. 2 (Art. I Nr. 4 [zu Art. 63 Abs. 3 und 4]).

72 Ursprünglich war ein Volksentscheid zur Auflösung des Landtags, dem freilich ein Volksbegehren mit einer 20-Prozent-Hürde vorausging, sogar quorenlos (vgl. Art. 109 Abs. 1 b, Abs. 3 S. 1, Abs. 4 S. 2 Verf. a.F.). 2000 wurde ein Beteiligungsquorum von 25 Prozent eingeführt (Art. 109 Abs. 4 S. 3 Verf. n F.), vgl. D. Franke, in: C. Grimm/P. Caesar (Hrsg.), Verfassung für Rheinland-Pfalz. Kommentar, Baden-Baden 2001, Art. 109 Rn. 1. Für die verfassungsändernde Volksgesetzgebung hingegen galt immer ein $\mathrm{Zu}-$ stimmungsquorum von 50 Prozent (Art. 129 Abs. 1 Verf.).

Vgl. O. Jung, Jüngste plebiszitäre Entwicklungstendenzen in Deutschland auf Landesebene, in: JöR 41 (1993), S. 29-67 (35-40, 65 f.); dens., Abschluß (Fn. 5), S. 78 f. 
gehrenshürde von fünf Prozent relativ leicht ist, scherte gar nicht; für das Volksbegehren hielt man sich quasi-selbstverständlich wieder an die eigenen Berliner Regeln, aber nicht etwa, was historisch-systematisch gestimmt hätte, an die Regeln der Verfassung von 1950 für die (verfassungsändernde) Volksgesetzgebung, sondern an die geltenden Regeln für die direktdemokratische Auflösung des Abgeordnetenhauses - eine Gleichsetzung, die am Schluß des Verfahrens, bei den Quoren für den Volksentscheid, dann wiederum - wie gezeigt - nicht durchgehalten wurde. All dies geschah ohne irgendeine nachvollziehbare Begründung. Die Verantwortlichen pflogen hier einen Eklektizismus, der sich aus eigenem und fremdem Normenmaterial herausgriff, was gefiel, und auf systematische Anstrengungen ebenso verzichtete wie auf die Pflege verfassungshistorischer Traditionen. Offensichtlich kam das „Rosinen-Herauspicken“, das - wie erwähnt - der Thüringer Verfassungsgerichtshof 1999 einem volksbegehrten Entwurf für eine Neuregelung der Volksgesetzgebung vorgeworfen hatte ${ }^{74}$, auch auf der repräsentativ-demokratischen Ebene bei der Arbeit einer interfraktionellen Arbeitsgruppe vor, wobei man das Sprachbild wegen des abwehrenden Charakters all dieser Klauseln wohl zu „Zitronen-Pflücken“ variieren sollte. Und vermutlich verstanden jene, die „oben“ eklektisch nach Früchten suchten, ihr Tun ebenso wie die Geistesverwandten ,unten“ nur als Optimierung eines Regelwerks im gewünschten Sinne.

Das Erfordernis einer Zweidrittel-Mehrheit der Abstimmenden und ein 50prozentiges Zustimmungsquorum stellen die schwerste Hürde dar, die das deutsche Landesverfassungsrecht kennt. Daß Berlin sich damit in Gesellschaft fünf anderer Bundesländer befand ${ }^{75}$, sei fairerweise festgestellt, ebenso freilich, daß fünf andere Bundesländer ein 50prozentiges Zustimmungsquorum allein ausreichen lassen ${ }^{76}$ und daß dieses Quorum in Thüringen bei 40 Prozent $^{77}$ und in Bayern bei 25 Prozent $^{78}$ liegt $^{79}$. Festzuhalten ist allerdings auch, daß dieses ganze Quoren-

74 ThürVerfGH, Urt. v. 19.9.2001, LVerfGE 12, 405-463 (442).

75 Brandenburg (Art. 78 Abs. 3 S. 1), Hamburg (Art. 50 Abs. 3 S. 5 a.F.), MecklenburgVorpommern (Art. 60 Abs. 4 S. 2), Sachsen-Anhalt (Art. 81 Abs. 5) und SchleswigHolstein (Art. 42 Abs. 4 S. 2). - 2008 hat Hamburg das starre Quorum aufgehoben und durch eine Anbindung an die Partizipation bei der gleichzeitigen Parlamentswahl ersetzt (Art. 50 Abs. 3 S. 11 n. F.), vgl. A. v. Arnauld, „Refolution“ an der Elbe: Hamburgs neue direkte Demokratie - Die Verfassungsänderungen der Jahre 2008 und 2009 im Kontext, in: JdD 1 (2009), S. 90-130 (112): „Synchronisierung der Legitimationsniveaus direkter und repräsentativer Demokratie“.

76 Baden-Württemberg (Art. 64 Abs. 3 S. 3), Bremen (Art. 72 Abs. 2), Niedersachsen (Art. 49 Abs. 2 S. 2), Rheinland-Pfalz (Art. 129 Abs. 1) und Sachsen (Art. 74 Abs. 3 S. 3).

77 Art. 83 Abs. 2 S. 2. Bei der Reform des direktdemokratischen Regelwerks 2003 wurde dieses Quorum von 50 auf 40 Prozent gesenkt.

78 Für den von den Verfassungseltern quorenlos konzipierten Volksentscheid stellte der Bayerische Verfassungsgerichtshof 1999 durch richterrechtliche Verfassungsänderung ein 25prozentiges Zustimmungsquorum auf. 
wesen eine spezifisch deutsche Hervorbringung ist. In den alten demokratischen Republiken mit direkter Demokratie - der Schweiz auf allen staatlichen Ebenen und den US-Bundesstaaten - sind solche Quoren unvorstellbar; sie gelten dort als Verletzung des Mehrheitsprinzips.

Warum die Reformer in Berlin diese extremen Anforderungen aufgestellt haben, ist unerfindlich ${ }^{80}$. Hätte sich Berlin schon 1995 zu dieser Lösung entschlossen, hätte es nun - elf Jahre später - eine echte Reform des Regelwerks in Richtung auf mehr Praktikabilität vornehmen können, etwa wie Thüringen, das sein 1994 aufgestelltes 50prozentiges Zustimmungsquorum bei der Reform 2003 auf 40 Prozent gesenkt hat. Berlin scheint, wie dieser Vergleich zeigt, in puncto direkte Demokratie um ganze verfassungspolitische Etappen nachzuhinken. Hinzu kommt die parteipolitische Paradoxie ${ }^{81}$ : Die skizzierte Erleichterung der direkten Demokratie in Thüringen hat 2003 vor allem eine mit absoluter Mehrheit regierende CDU getragen, während die vergleichsweise ängstlichen Klauseln bei der Berliner Reform 2006 wesentlich von der SPD und eben der eigentlich opponierenden CDU durchgesetzt wurden.

Überlegung und Erfahrung zeigen, daß schon bei einem 50prozentigen $\mathrm{Zu}$ stimmungsquorum verfassungsändernde Volksgesetzgebung nicht möglich ist ${ }^{82}$.

79 Dazu kommen drei Sonderfälle: In Hessen ist nach richtiger, aber umstrittener Auslegung auch der verfassungsändernde Volksentscheid - ebenso wie ursprünglich in Bayern quorenlos (Art. 124 Abs. 3 S. 2). Nordrhein-Westfalen verlangt eine Zweidrittel-Mehrheit der Abstimmenden bei einem Beteiligungsquorum von 50 Prozent (Art. 69 Abs. 3 S. 3). Im Saarland ist die verfassungsändernde Volksgesetzgebung imperfekt, d.h. es findet über einen solchen volksbegehrten Entwurf überhaupt kein Volksentscheid statt (Art. 100 Abs. 4).

80 In diesem Zusammenhang wäre es übrigens ein Mißverständnis, dem Verfasser seine frühere Frage entgegenzuhalten: „Hätte gegebenenfalls nicht eine Erhöhung dieses Schutzes auf den derzeitigen Maximalstand eines 50prozentigen Zustimmungsquorums plus einer Zweidrittelmehrheit der abgegebenen gültigen Stimmen ausgereicht?" So Jung, Abschluß (Fn. 5), S. 65. Damals ging es darum, zu zeigen, daß es nicht nötig gewesen war, die verfassungsändernde Volksgesetzgebung zu tabuisieren, sondern daß man sie auch - zur Beruhigung aller Ängstlichen - erst einmal hätte „,verbauen“ können; ein grundsätzliches verfassungspolitisches Votum für ein derart hohes Quorum war damit keineswegs verbunden.

81 Zur grundsätzlichen, auch programmatischen Positionierung der (Bundestags-)Parteien in Deutschland zur direkten Demokratie vgl. O. Jung, Volksentscheid ins Grundgesetz? Die politische Auseinandersetzung um ein rot-grünes Reformprojekt 1998-2002, in: ZfP 49 (2002), S. 267-289; dens., Direkte Demokratie. Die Angst der politischen Klasse vor dem Volk: Fortschritte und Rückschritte in den letzten 15 Jahren in Deutschland, in: H.H. v. Arnim (Hrsg.), Defizite in Staat und Verwaltung. Beiträge auf der 10. Speyerer Demokratietagung vom 25. und 26. Oktober 2007 an der Deutschen Hochschule für Verwaltungswissenschaften Speyer, Berlin 2010 (Schriftenreihe der Hochschule Speyer Bd. 203), S. 105-171 (156 f.).

82 Vgl. O. Jung, Das Quorenproblem beim Volksentscheid. Legitimität und Effizienz beim Abschluß des Verfahrens der Volksgesetzgebung, in: ZPol 9 (1999), S. 863-898 (893); 
Wird dieses Zustimmungsquorum noch mit dem Erfordernis einer internen Qualifizierung (Zweidrittel-Mehrheit der Abstimmenden) kombiniert, bedeutet dies die endgültige Verriegelung des Verfahrens ${ }^{83}$. Es handelt sich dann um einen Fall symbolischer Politik: Den Bürgerinnen und Bürgern wird feierlich ein Recht eingeräumt, für dessen Verwirklichung die Aussichten bei Null liegen. Von den Verantwortlichen hat dies mancher durchaus gesehen. Der FDP-Unterhändler sprach es bei der I. Lesung im Abgeordnetenhaus offen aus: „Ganz absurd wird es [sc. mit den Quoren] dann bei Verfassungsänderungen, denn dabei sind 1,2 Millionen Ja-Stimmen nötig. Sie sind sozusagen formal möglich, de facto aber ausgeschlossen. ${ }^{\text {“84 }}$ Der Fachverband Mehr Demokratie urteilte in einer fast zu subtilen Unterscheidung: „Bisher waren Volksbegehren und Volksentscheide zur Verfassung überhaupt nicht möglich, in Zukunft sind sie gar nicht möglich.“ ${ }^{\text {(85 }}$ Juristisch könnte man pointieren: Bisher war verfassungsändernde Volksgesetzgebung unzulässig; künftig ist sie möglich, aber chancenlos. Doch solche Pointierungsversuche geraten zu knapp. Angemessen läßt sich die Reform an diesem Punkt etwa so zusammenfassen: Der Anstoß der bisherigen Verfassungsrechtslage, welche die verfassungsändernde Volksgesetzgebung tabuisierte, ist ausgeräumt. Künftig ist im Wege der Volksgesetzgebung auch eine Verfassungsänderung zulässig; das sei anerkannt. Aber am Ende des neu eingeführten Verfahrens zur direktdemokratischen Verfassungsänderung haben die Reformer eine extrem hohe Hürde aufgerichtet. Bestünde jemals die begründete Aussicht, diese Hürde

ders., Abschluß (Fn. 5), S. 81. - Nach S. Przygode, Die deutsche Rechtsprechung zur unmittelbaren Demokratie. Ein Beitrag zur Praxis der Sachentscheide in Deutschland, Baden-Baden 1995 (Fundamenta Juridica Bd. 28), S. 474, macht ein solches Quorum, unabhängig davon, ob es im Grundverfahren oder bei der verfassungsändernden Volksgesetzgebung verlangt wird, ,jeden Volksentscheid zur Farce“.

83 J. Rux, Direkte Demokratie in Deutschland. Rechtsgrundlagen und Rechtswirklichkeit der unmittelbaren Demokratie in der Bundesrepublik Deutschland und ihren Ländern, Baden-Baden 2008, S. 901 Fn. 2, spricht von „exorbitant hohen Quoren“ und davon, daß dieses Quorum „fast unerreichbar hoch“ sei. - Pestalozzas (Auf gutem Weg [Fn. 33], S. 316) knappe Sentenz: „Die Quoren lassen Mißbrauchssorgen nicht aufkommen“, wirkt unfreiwillig (?) ironisch.

84 Abg. Ritzmann (FDP), AH 4.5.2006, S. 7347 D. Der Redner fuhr vielsagend fort: „Auch hier gehört es zur Ehrlichkeit, daß wir darüber sprechen. Das ist gewissen skeptischen Herangehensweisen geschuldet.“ - Bei einer Podiumsdiskussion fünf Wochen zuvor hatte Ritzmann sogar von „Scheindemokratie“ gesprochen, der Abg. Volker Ratzmann (Bündnis 90/Die Grünen) hatte diese Klauseln als „,nicht hinnehmbar“ bezeichnet, und der Abg. Lederer (Linkspartei.PDS), der Dritte aus der interfraktionellen Arbeitsgruppe, der an diesem Punkt in der Minderheit geblieben war, hatte kühl analysiert, daß mit solchen Quoren Volksentscheide „nur auf dem Papier möglich wären“, vgl. den Kurzbericht über das öffentliche Hearing ,Wie viel Demokratie wollen wir wagen?“ am 27.3.2006, http://www.du-entscheidest-mit.de/uploads/media/Kurzbericht.pdf (Zugriff 31.10.2006).

85 Mehr Demokratie e.V.: Du entscheidest mit! Die Reform, http:/www.du-entscheidestmit.de/804.99.html (Zugriff 12.8.2006). 
zu überwinden - d.h. also, daß zwei Drittel der Abstimmenden und zugleich mindestens die Hälfte der Stimmberechtigten an den Urnen für eine Verfassungsänderung votierten, welche die Regierung und die sie tragende Parlamentsmehrheit hartnäckig ablehnten -, läge objektiv eine revolutionäre Situation vor. Das wäre dann nicht mehr (nur) Volksgesetzgebung, sondern offenbarte zugleich eine Staatskrise.

\subsubsection{Die Einschränkung des Finanztabus}

Die Abkehr von den bisherigen Tabuisierungen ist ein kennzeichnender Zug der Reform. Bei der Einwohnerinitiative wurden alle Tabus gestrichen und beim Volksbegehren das Verfassungstabu. Das Finanztabu wurde zumindest eingeschränkt. Dieser Reformschritt ist nicht ohne das Urteil des Verfassungsgerichtshofs vom 22. November $2005^{86} \mathrm{zu}$ verstehen, mit dem die Unzulässigkeit des Volksbegehrens „Schluß mit dem Berliner Bankenskandal““ endgültig festgestellt wurde. Es war dies die erste Entscheidung des Gerichtshofs zu der Finanzausschlußklausel der Verfassung, die darin vorgenommene weite Auslegung war knapp gesagt - konventionell, aber das Urteil schuf in bemerkenswerter Weise keinen Rechtsfrieden, sondern löste umgehend Bestrebungen zur Reform der entscheidungsmaßgeblichen Norm aus. Deren Änderung gehört gewiß zu den interessantesten und vielleicht am ehesten in die Zukunft weisenden Partien der Reform. Man kann in dieser Antwort des verfassungsändernden Gesetzgebers auch die politische Botschaft an den Verfassungsgerichtshof sehen, daß er mit seinem Urteil zu weit gegangen sei, ja in gewisser Weise könnte man darin sogar eine Desavouierung des Gerichtshofs erblicken.

Schon 2000 wollte die PDS das Finanztabu auf das „Haushaltsgesetz (Art. 85 Abs. 1 S. 1 VvB)“ reduzieren $^{87}$. Den neuen Reigen der Reformvorschläge eröffneten die Grünen mit ihrem Antrag vom 16. November 2005 - also sechs Tage vor Verkündung des verfassungsgerichtlichen Urteils; die Fraktion hörte da sozusagen „das Gras wachsen“-, der das Finanztabu künftig auf solche Volksbegehren beschränken wollte, ,die unmittelbar auf den Landeshaushalt“ gerichtet seien. „Mittelbare Auswirkungen auf den Haushalt stehen Volksbegehren nicht entgegen.“ Zukunftsweisend war auch die Bestimmung: „Soweit der Gegenstand eines Begehrens Ausgaben nach sich zieht, die 0,5 Prozent des Volumens der steuerbaren Ausgaben überschreiten, muß die Deckung innerhalb des Haushalts nachgewiesen werden." In der Begründung hieß es dazu treffend, die bisherige

87 Drs. 14/655 v. 14.9.2000, S. 1 (Art. I Nr. 2 [zu Art. 61 Abs. 4]) und S. 2 f. (Begründung zu Art. 61 Abs. 4). 
Ausschlußklausel, „mit der alle Begehren, die in irgendeiner Weise z.B. den Haushalt betrafen, von vornherein ausgeschlossen waren bzw. nachträglich für verfassungswidrig erklärt wurden“, stelle eine der höchsten Hürden für Volksbegehren dar ${ }^{88}$. Der Gesetzentwurf des Bündnisses gut drei Monate später formulierte noch straffer: „Volksbegehren über das Haushaltsgesetz ... sind unzulässig. Finanzwirksame ... Volksbegehren sind zulässig. “89 Dazu führte das Bündnis aus: „Stellt man alle Volksbegehren unter einen Haushaltsvorbehalt, so ist eine realistische Mitsprache der Bürgerschaft nicht gegeben, denn Politik ohne finanzielle Folgewirkungen ist kaum denkbar. Die Budgethoheit des Parlaments bleibt gleichwohl bestehen." Man könnte diese neueren Reformvorschläge auch als den Versuch bezeichnen, die Rechtsprechung des Sächsischen Verfassungsgerichtshofs in seinem wegweisenden Urteil von 2002 zum Volksantrag „Zukunft braucht Schule “90 als künftiges Berliner Verfassungsrecht festzuschreiben.

Es erscheint bemerkenswert, wie rasch die großen politischen Parteien sich in diese Richtung bewegten. Schon in der dritten Januarwoche 2006 wurde eine Einigung der Fachleute der Koalitionsparteien SPD und Linkspartei.PDS darüber gemeldet, daß künftig „Plebiszite“ möglich sein sollten, „die den Landeshaushalt betreffen“"91. Volksbegehren sollten ,auch dann erlaubt sein, wenn sie finanzielle Auswirkungen haben“92. Die interfraktionelle Arbeitsgemeinschaft aller Parteien schloß sich dieser Position an, entschied sich aber Mitte März für eine andere Regelungstechnik. Im Text der Verfassung sollte nur der Begriff „Landeshaushalt" durch den Begriff „Landeshaushaltsgesetz“ ersetzt werden. Die korrespondierende Bestimmung, daß finanzwirksame Volksbegehren zulässig seien, wurde in die Begründung des geplanten Änderungsgesetzes verwiesen. Auf Wunsch der SPD kam noch eine Passage über das parlamentarische Budgetrecht hinzu. Während der weiteren Beschäftigung der Arbeitsgruppe mit diesem Punkt wurde die Begründung immer umfangreicher, so daß der schließlich im Parlament eingebrachte All-Parteien-Antrag im Rahmen einer Begründung, die sonst oft dürftig gehalten war bzw. sich auf eine Paraphrase der neuen Normen beschränkte, an

88 Drs. 15/4472 v. 16.11.2005, Art. I Nr. 2 d (zu Art. 62 Abs. 6) u. Begründung dazu (S. 3).

89 Vgl. Bündnis, Entwurf (Fn. 17), Nr. 4, Vorschlag zu Art. 62 Abs. 1 S. 2 u. 3.

90 SächsVerfGH, Urteil v. 11.7.2002, LVerfGE 13, 315-339. - Vgl. dazu O. Jung, Direkte Demokratie - vom Kopf auf die Füße gestellt. Ein Urteil des Verfassungsgerichtshofes des Freistaates Sachsen eröffnet die Debatte neu, in: LKV 13 (2003), S. 308-314, und H.$J$. Wiegand, Direktdemokratische Elemente in der deutschen Verfassungsgeschichte, Berlin 2006 (Juristische Zeitgeschichte Abt. I Bd. 20), S. 490-494.

91 Vgl. U. Zawatka-Gerlach, Mehr Macht für den Regierenden und das Volk, in: Tsp. Nr. 19077 v. 18.1.2006. Die Meldung lautete weiter: „Zur Zeit sind Volksbegehren ,zum Landeshaushalt' verboten. Im November war die Bürgerinitiative zum Bankenskandal daran gescheitert.“

92 Vgl. U. Zawatka-Gerlach, Mehr Macht für den Regierungschef, in: Tsp. Nr. 19079 v. 20.1.2006. 
dieser Stelle zu dem erwähnten Begriffsaustausch nicht weniger als drei wortreiche Absätze aufbot:

„Das Ausschlußkriterium ,Landeshaushalt“ wird in ,Landeshaushaltsgesetz geändert. Damit wird nur klargestellt, daß Volksbegehren auch dann zulässig sein können, wenn sie Einnahmen oder Ausgaben auslösen. Die Volksgesetzgebung wird nicht unter einen pauschalen Finanzvorbehalt gestellt, da sonst weite Regelungsbereiche von der direkten Demokratie ausgeschlossen wären. Dies entspricht im übrigen der bisherigen Rechtslage.

Die Grenze, ab wann ein finanzwirksames Volksbegehren den ,Landeshaushalt' verletzt, ist verfassungsrechtlich nicht bestimmbar. Deshalb war es erforderlich, die Klausel auf den Begriff des ,Haushaltsgesetzes' zu konkretisieren, was seine Bestandteile und damit auch den Haushaltsplan umfaßt. Dieses ist für die Volksgesetzgebung schon deshalb ungeeignet, weil es in einem festen zeitlichen Rahmen verabschiedet werden muß. Auch eignet sich die auf ein konkretes Vorhaben zugeschnittene direkte Demokratie nicht als Instrument der globalen Steuerung durch das Haushaltsgesetz, welches dem Parlament vorbehalten bleibt.

Volksgesetzgebung und direkte Demokratie finden auch jenseits des Landeshaushaltsgesetzes in der Verfassung selbst ihre immanenten Grenzen im Budgetrecht des Parlaments sowie in den Anforderungen an einen verfassungsgemäßen Haushalt, für den das Parlament die alleinige Verantwortung trägt." ${ }^{\text {"93 }}$

Die Feststellung, daß die Grenze, ab wann ein finanzwirksames Volksbegehren den „Landeshaushalt“ verletze, verfassungsrechtlich „,nicht bestimmbar“ sei, bedeutete eine Ohrfeige sowohl für den Verfassungsgeber, der das Finanztabu 1995 in dieser Form aufgestellt hatte, als auch für den Verfassungsgerichtshof wegen dessen, was er 2005 aus dieser mißratenen Norm gemacht hatte. Ansonsten fallen die „,beruhigenden“, um nicht zu sagen ,abwiegelnden“ Formulierungen auf: ,wird nur klargestellt“, „entspricht im übrigen der bisherigen Rechtslage“, „,ist für die Volksgesetzgebung schon deshalb ungeeignet“, „finden ... ihre immanenten Grenzen“ - die durchaus keinen Widerspruch erfordern, aber eben doch viel über die Mentalität und die Sorgen der Reformer verraten. Die GrünenIdee der Pflicht zu einem Deckungsvorschlag wurde aufgegriffen, aber an wieder eine andere Stelle verwiesen: „Die Frage, wie die nötige Kostentransparenz geschaffen werden kann, damit die Bürgerinnen und Bürger auch wissen, welche finanziellen Auswirkungen ihre Entscheidungen haben, soll im Ausführungsgesetz ähnlich geregelt werden wie beim Bürgerbegehren und Bürgerentscheid." “94

Warum die interfraktionelle Arbeitsgruppe diese Regelungstechnik wählte, also den eigentlichen Neuzuschnitt des Finanztabus im Verfassungstext derart ver-

94 Ebenda. 
knappte, ist unerfindlich. Festzuhalten ist nur der Kontrast zu dem ansonsten oft umständlich-weitschweifigen Duktus der Verfassung ${ }^{95}$, und hinzuweisen ist auf die Konsequenzen für die Verfassungsinterpretation.

Was die Folgen dieses Reformschritts angeht, fällt die verbreitete Unsicherheit ins Auge - auf etlichen Seiten ${ }^{96}$. Parlamentspräsident Momper bezeichnete die Einschränkung des bisherigen Finanztabus zwar als Fortschritt, räumte aber ein, „daß es problematisch werden könne, wenn Entscheidungen der Bürger nicht finanzierbar seien. Hier müsse man , in der Praxis sehen, wie das funktioniert'. Aber wenn man von vornherein Gegenstände ausschließt, weil man sagt, die sind nicht finanzierbar, dann schließt man natürlich einen ganz großen Teil aus ““97. Das Bündnis argumentierte ähnlich. Daß finanzwirksame Volksbegehren nicht mehr von vornherein ausgeschlossen seien, sei positiv zu bewerten. „Abzuwarten bleibt, wie diese Änderung von Senat und Landesverfassungsgericht ausgelegt wird. “98 Auch der Matador von Mehr Demokratie bei der Reform, Efler, war von Anfang an skeptisch: „Ob es einen Unterschied macht, wenn nicht mehr der gesamte Landeshaushalt, sondern nur noch das Haushaltsgesetz ausge-

95 Gerade die Bestimmungen über Volksbegehren und Volksentscheid sind voll Selbstverständlichem und Überflüssigem: „Volksbegehren können darauf ausgerichtet werden, Gesetze zu erlassen, zu ändern oder aufzuheben“; mußte man hinzufügen ,soweit das Land Berlin die Gesetzgebungskompetenz hat" (Art. 62 Abs. 1 S. 1 VvB)? Wer kommt schon auf die Idee, mit einem Berliner Volksbegehren ein Bundesgesetz aufheben oder ein Gesetz eines anderen Bundeslandes ändern zu wollen? Rechtstechnisch durchgearbeitete Verfassungen enthalten keine solchen Redundanzen, vgl. hier Art. 109 Abs. 1 Nr. 1 Verf. RP. Kommt ein Volksgesetz zustande, verkündet es der Regierende Bürgermeister „im Gesetz- und Verordnungsblatt für Berlin“ (Art. 63 Abs. 4 VvB a.F., Art. 62 Abs. 5 VvB n.F.). Warum wird das Verkündungsblatt eigens genannt? Bei der parlamentarischen Gesetzgebung erscheint dies mit Recht unnötig (vgl. Art. 60 Abs. 2 VvB). Und was soll die Präzisierung, daß die Verkündung im Gesetz- und Verordnungsblatt „für Berlin“ erfolgen solle? Besteht ohne diesen Zusatz die Gefahr, daß der „Regierende“ das Volksgesetz womöglich im Gesetz- und Verordnungsblatt für das Land Brandenburg verkündet (vgl. Art. 71 Abs. 1 S. 1 Verf. NRW)? Man stellt Regeln auf für ein Volksbegehren, das einen „die Verfassung von Berlin“ ändernden Gesetzentwurf zum Gegenstand hat (Art. 63 Abs. 2 S. 1, vgl. S. 3). Versteht sich nicht von selbst, daß ein Berliner Volksbegehren weder die Verfassung des Bundes noch eine andere Landesverfassung ändern kann (vgl. dagegen wieder Art. 69 Verf. NRW und auch schon Art. 88 Abs. 2 VvB 1950)? - Siehe zu diesen Redundanzen bereits C. Pestalozza, Die überarbeitete Verfassung von Berlin. Integrationsbeitrag und Fusionsmitgift, in: LKV 1995, S. 344-353 (351); dens., Auf gutem Weg (Fn. 33), S. 302, 306.

96 Die Protokolle der parlamentarischen Behandlung dieses Punktes im Plenum des Abgeordnetenhauses und im Verfassungsausschuß sind unergiebig.

97 Interview v. 25.8.2006: „Mehr Volksentscheide in der Hauptstadt?“ http://www.inforadio.de/static/dyn2sta_article/835/138835_article.shtml (Zugriff 17.9.2006), vgl. „Momper für die Stimme des Volkes“, in: http://www.tagesspiegel.de/tso/drucken.asp?TextID=71878 (Zugriff: 26.8.2006).

98 Berlin wird demokratischer (Fn. 12). 
nommen ist, muß die Praxis zeigen. ${ }^{\text {“99 }}$ Kurz vor der Abstimmung antwortete er in einem Interview auf die Frage, ob der „Haushaltsvorbehalt ... jetzt vom Tisch“ sei: „Das ist unklar. Bisher heißt es in der Landesverfassung, Volksbegehren ,zum Landeshaushalt‘ seien unzulässig. Künftig soll es ,zum Landeshaushaltsgesetz' heißen. Wir verstehen diese Änderung so, daß sie eine substantielle Erweiterung der Möglichkeiten ist, in den Haushalt einzugreifen, und daß es damit leichter sein wird, Volksbegehren gegen Sparmaßnahmen bei Kitas, Hochschulen oder auch in anderen Bereichen durchzusetzen. Ob die neue Regelung aber auch dazu führen wird, daß Volksbegehren wie jenes zum Bankenskandal in $\mathrm{Zu}-$ kunft zulässig sein werden, kann man heute noch nicht sagen. Das wird eine Frage der politischen und juristischen Auseinandersetzung sein. Leider herrscht in Deutschland immer noch die Vorstellung vor, man müsse die Bürger von den Finanzen fernhalten, sie könnten nicht über ihre eigenen Steuergelder mitentscheiden. “100

Jene Unsicherheit hatte einen klar benennbaren Grund: Was der Verfassungsgerichtshof aus der Reform der direkten Demokratie an dieser Stelle machen würde, war ziemlich offen. Ob der verfassungsändernde Gesetzgeber - unter Zustimmung des Souveräns! - die an die Verfassung gebundenen Richter dieses Gerichtshofs bei ihrer künftigen Auslegung des Finanztabus in dem beabsichtigten Sinne steuern könnte, ob diese die oben erwähnte „Desavouierung“ bzw. gar die „Ohrfeige“ hinnehmen würden, mußte in der Tat mit Skepsis abgewartet werden. Zwei objektive Gründe für diese Einschätzung lagen in Schwächen der Verfassungsreformarbeit. Da war erstens die unklare Terminologie: Zunächst mochte die Einschränkung des Finanztabus von bisher dem „Landeshaushalt“ auf künftig das „Landeshaushaltsgesetz“ eindeutig erscheinen. Indes ist der Terminus technicus der Begriff des „Haushaltsgesetzes“; Art. 85 Abs. 1 S. 1 VvB gibt eine Legaldefinition: Durch das „Haushaltsgesetz“ wird der Haushaltsplan, in dem alle Einnahmen und Ausgaben für jedes Rechnungsjahr veranschlagt werden müssen, festgestellt. Schon bei der grammatikalischen Auslegung bot also der Umstand, daß die Reformer das neue Tabu eben nicht mit „Haushaltsgesetz" umschrieben hatten - auch wenn sie es ausweislich der Begründung so meinten ${ }^{101}$-, sondern mit „Landeshaushaltsgesetz“, Ansätze zum Deuteln ${ }^{102}$. Vor

99 Mehr Demokratie e.V., Bundesverband, Presseinformation Nr. 16/06 v. 18.5.2006.

100 „Volksbegehren sind dann eher durchsetzbar“, in: Junge Welt Nr. 210 v. 11.9.2006.

101 Vgl. dazu aus der oben zitierten Begründung: ,... erforderlich, die Klausel auf den Begriff des ,Haushaltsgesetzes‘ zu konkretisieren“, Drs. 15/5038 v. 26.4.2006, S. 6 (Begründung zu Art. I Nr. 8 [zu Art. 62 Abs. 2]). - Warum die Reformer nicht die eindeutige Formulierung aus dem PDS-Entwurf von 2000 (,,zum Haushaltsgesetz [Art. 85 Abs. 1 S. 1 VvB]“) aufnahmen, ist unerfindlich.

102 Ist das wieder eine der bekannten Redundanzen dieser Verfassung, oder hat die terminologische Differenz eine Bedeutung? Bereits unter der bisherigen Rechtslage hatte der 
allem aber lehrt die Erfahrung, daß selbst bei terminologischer Übereinstimmung ein Gericht Begriffe je nach ihrer Stellung in der Verfassung verschieden auslegen kann. Die Rechtsprechung des Bayerischen Verfassungsgerichtshofs zu der scheinbar so klaren Bestimmung des Art. 73 BayVerf., wonach über den „Staatshaushalt“ kein Volksentscheid stattfindet, ist ein schlagendes Beispiel. Obwohl der Terminus nach der Begrifflichkeit der Verfassung eindeutig den durch Gesetz festgestellten Haushaltsplan bezeichnet (vgl. Art. 70 Abs. 2, 78 Abs. 4 BayVerf.), erklärt der Bayerische Verfassungsgerichtshof jedes finanzwirksame Volksbegehren oberhalb einer Bagatellgrenze für unzulässig ${ }^{103}$. Dies ist keine Besonderheit jenes Freistaats. Bei der Auslegung des Finanztabus ist durchweg zu beobachten, daß sich die Verfassungsgerichte der Länder von der jeweiligen Formulierung der einschlägigen Klauseln in den Landesverfassungen wenig ,stören“ lassen ${ }^{104}$.

Eine zweite und womöglich geradezu verhängnisvolle Schwäche stellte die von den Reformern gewählte Regelungstechnik dar. Hätte man entsprechend dem Vorschlag der Grünen (2005) und des Bündnisses (2006) den Satz „Finanzwirksame Volksbegehren sind zulässig“" in den Verfassungstext hineingeschrieben, hätten die Verfassungsrichter eine echte Norm gehabt, an der sie sich hätten abarbeiten müssen. So stand das sinngemäß nur in der Begründung und gehörte damit - wie die drei wortreichen einschlägigen Absätze insgesamt - methodologisch nur zur sogenannten historisch-genetischen Interpretation des Finanztabus aus der Entstehungsgeschichte der Norm, und diese historische Interpretation ist nach der von der herrschenden Meinung bevorzugten sogenannten objektiven Auslegungstheorie die schwächste Methode im Konzert der Ausle-

Verfassungsgerichtshof sich bei der grammatikalischen Auslegung auf ,die anders lautende Wortwahl in Art. 62 Abs. 5 VvB“ (sc. gegenüber Art. 85 Abs. 1 S. 1 VvB) gestützt, vgl. Urteil v. 22.11.2005, LVerfGE 16, 41 (61).

103 Vgl. die Kritik bei K. Schweiger, in: H. Nawiasky/ders./F. Knöpfle (Hrsg.), Die Verfassung des Freistaates Bayern. Kommentar, München (12. Lieferung 2003), Art. 73 Rn. 5. Siehe dens., Weiterentwicklung der verfassungsgerichtlichen Rechtsprechung zum Plebiszit, in: BayVB1. 2005, S. 321-332.

104 Vgl. O. Jung, Das Finanztabu bei der Volksgesetzgebung. Die Staatsrechtslehre und Staatspraxis der Weimarer Zeit, in: Der Staat 38 (1999), S. 41-68 (44, 68); dens., Unverdient höchster Segen. Das BVerfG folgt der (wenig überzeugenden) Rechtsprechung der Landesverfassungsgerichte zum Finanztabu bei der Volksgesetzgebung, in: NVwZ 2002, S. 41-43 (41 f.); J. Krafczyk, Der parlamentarische Finanzvorbehalt bei der Volksgesetzgebung. Perspektiven für eine nähere Bestimmung der Zulässigkeit direktdemokratischer Entscheidungen mit Auswirkungen auf den Haushalt de lege lata und de lege ferenda, Berlin 2005 (Schriften zum Öffentlichen Recht Bd. 980), S. 89; T. Rosenke, Die Finanzbeschränkungen bei der Volksgesetzgebung in Deutschland. Unter besonderer Berücksichtigung des Artikels 68 Absatz 1 Satz 4 der nordrhein-westfälischen Verfassung, Baden-Baden 2005, S. 212. 
gungsinstrumente ${ }^{105}$. Wiederum bot die einschlägige Rechtsprechung des Bayerischen Verfassungsgerichtshofs einen negativen Anschauungsunterricht, wie wenig selbst die klarsten Absichten der Verfassungseltern später zählen ${ }^{106}$.

$\mathrm{Zu}$ befürchten stand, daß der Verfassungsgerichtshof bei einer genetischen Interpretation wie folgt argumentierte: Trotz entsprechender Vorschläge habe sich der verfassungsändernde Gesetzgeber nicht dazu entschlossen, im Anschluß an die Neuformulierung des Finanztabus etwa den Satz „Finanzwirksame Volksbegehren sind zulässig“" als Art. 62 Abs. 2 S. 2 VvB in den Verfassungstext zu setzen, und ihn statt dessen bloß sinngemäß in die Begründung aufgenommen. Dies genüge nicht. „Die für alle verbindlichen Gebote und Verbote müssen auf Gesetz beruhen“ (Art. 59 Abs. $1 \mathrm{VvB}$ ); dies gelte erst recht für die grundlegenden Bestimmungen der Verfassung. Begründungen sollten Rechtsänderungen erläutern, könnten sie aber nicht ersetzen. Sehe das Parlament davon ab, eine Norm zu schaffen, sei mit der anderweitigen Niederlegung von Maximen, Einschätzungen und Absichten (denn eine „Begründung“ im herkömmlichen Sinne war das ja gar nicht), denen keine normative Kraft zukomme, auch nicht gedient. Der Gesetzgeber habe den Sachverhalt dann eben nicht (rechtstechnisch) anders ${ }^{107}$, sondern (normativ) gar nicht geregelt.

Freilich muß man, leicht resigniert, einräumen, daß selbst eine andere Regelungstechnik der Reformer - die ausdrückliche Aufnahme jenes Satzes in den

105 Für eine „Rehabilitierung“ der historisch-genetischen Methode plädiert H.-P. Schneider, Der Wille des Verfassunggebers. Zur Bedeutung genetischer und historischer Argumente für die Verfassungsinterpretation, in: J. Burmeister (Hrsg.), Verfassungsstaatlichkeit. Festschrift für Klaus Stern zum 65. Geburtstag, München 1997, S. 903-923. „Methodenfragen sind Machtfragen“, betont Rüthers; es geht „,bei der Frage der Auslegungsmethode um die Abgrenzung der Normsetzungsbefugnisse zwischen Parlament und Justiz“. „Die ,objektive“ Methode wird bevorzugt, weil sie den Gerichten ... beliebige Abweichungen von den erkennbaren Regelungszielen und Normzwecken der Gesetzgebung erlaubt, ohne daß sie diese Abweichungen offenlegen und begründen.“ Und „Methodenfragen sind Verfassungsfragen. ... Die Antworten darauf entscheiden darüber, ob die Bundesrepublik eine rechtsstaatliche Demokratie oder ein oligarchischer Richterstaat werden wird." So B. Rüthers, Methodenrealismus in Jurisprudenz und Justiz, in: JZ 2006, S. 53-60 (56 f., 60). Vgl. dens., Wer schafft Recht? - Methodenfragen als Macht- und Verfassungsfragen, in: JZ 2003, S. 995-997; dens., Demokratischer Rechtsstaat oder oligarchischer Richterstaat, in: JZ 2002, S. 365-371.

106 Vgl. C. Waldhoff, Verfassungsrechtliche Vorgaben für die Steuergesetzgebung im Vergleich Deutschland - Schweiz, München 1997 (Münchener Universitätsschriften. Reihe der Juristischen Fakultät, Bd. 121), S. 158-162; Rux, Direkte Demokratie (Fn. 83), S. 273-279; Krafczyk, Finanzvorbehalt (Fn. 104), S. 114-117.

107 Angesichts der umfänglichen und ungewöhnlichen „Begründung“ zu dem Punkt „Finanztabu" könnte man fast argwöhnen, in den Köpfen der Beteiligten habe sozusagen die Idee einer „kleinen Verfassungsänderung“ herumgespukt: nicht im Verfassungstext, sondern gewissermaßen im „Kleingedruckten“. - Dagegen lakonisch Pestalozza, Auf gutem Weg (Fn. 33), S. 309: Eine solche Klarstellung ,würde in die Verfassung gehören“. 
Verfassungstext - keinen Erfolg im gewünschten Sinne garantiert hätte. Nach der „objektiven Auslegungstheorie“ und mit dem Hebel der sogenannten teleologischen Auslegung ist alles möglich; damit können sich die Verfassungsrichter von den Steuerungsversuchen des Verfassungsgebers bzw. des verfassungsändernden Gesetzgebers faktisch befreien. Und da der Kampf um das Finanztabu, überblickt man die (landes-)verfassungsgerichtliche Rechtsprechung insgesamt $^{108}$, seit jeher mit den schwersten juristischen Waffen geführt wird und „demokratische Grundgedanken“ (Bayern ${ }^{109}$ ) bzw. ewigkeitsgarantierte Grundsätze (Thüringen ${ }^{110}$ ) aufgefahren werden, war die Berliner Reform der direkten Demokratie an dieser Stelle vielleicht zu schlicht angelegt.

Bittere Pointe: Ein Urteil wie jenes vom 22. November 2005 zur Unzulässigkeit des Volksbegehrens „Schluß mit dem Berliner Bankenskandal“, das die Aktivität des verfassungsändernden Gesetzgebers mit auslöste, könnte nach dieser Reform der direkten Demokratie, vielleicht mit einigen Adaptionen in der Argumentation, wieder ergehen ${ }^{111}$. „Brachte“ die Reform an dieser Stelle womöglich nicht mehr als eine gewisse Anhebung der erwähnten Bagatellgrenze? Und um das Wort „unerfindlich“ für die Wahl dieser Regelungstechnik aufzugreifen - sahen die Verantwortlichen das nicht, oder wollten zumindest die Großparteien dies gar nach dem Reform-Motto: „Wasch mir den Pelz, aber mach ihn mir nicht naß!"’?

Vor diesem Hintergrund ist die Erleichterung zu verstehen, mit der nach knapp drei Jahren der Unsicherheit das Urteil des Verfassungsgerichtshofs vom 6. Oktober 2009 (,Kitakinder“) aufgenommen wurde. Der Gerichtshof akzeptierte den Kern des Reformanliegens, ja die Verfassungsrichter revanchierten sich elegant, indem sie dem verfassungsändernden Gesetzgeber geradezu genüßlich lege artis vorführten ${ }^{112}$, daß er wirklich die Verfassung geändert hatte, während

108 Gute Überblicke und Analysen bieten F. Wittreck, Direkte Demokratie und Verfassungsgerichtsbarkeit. Eine kritische Übersicht zur deutschen Verfassungsrechtsprechung in Fragen der unmittelbaren Demokratie von 2000 bis 2002, in: JöR 53 (2005), S. 111-185; Krafczyk, Finanzvorbehalt (Fn. 104), S. 87-94; Rosenke, Finanzbeschränkungen (Fn. 104), S. 160-201; S. Jutzi, Volksgesetzgebung und Verfassungsrechtsprechung. Zu verfassungsrechtlich und verfassungsgerichtlich bestimmten Grenzen der Volksgesetzgebung, in: ZG 18 (2003), S. 273-292.

109 Vgl. BayVerfGH, Entscheidung v. 31.3.2000, BayVerfGHE 53, 42 (65), und dazu Wittreck, Direkte Demokratie (Fn. 108), S. 144 f.; Rux, Direkte Demokratie (Fn. 83), S. 279-282.

110 ThürVerfGH, Urteil v. 19.9.2001, LVerfGE 12, 405 (425), und dazu Wittreck, Direkte Demokratie (Fn. 108), S. 165.

111 In diesem Sinne betonte P. Michaelis-Merzbach, in: H.-J. Driehaus (Hrsg.), Verfassung von Berlin. Taschenkommentar, Baden-Baden 3. Aufl. 2009, Art. 62 Rn. 7, daß die Verfassungsänderung von 2006 ,die Möglichkeiten, finanzwirksame Volksbegehren durchzuführen, nicht etwa erweitert hat".

112 LVerfGE 20, 45 (58-64). 
der Senat in seiner Stellungnahme zu dem verhandelten Einspruch peinlicherweise den gerade angedeuteten Kurs einer Reform, die nichts änderte, zu fahren versucht hatte ${ }^{113}$. Ausgehend von der durch die Reformer beabsichtigten und bewirkten „erheblichen Erweiterung der Zulässigkeit von finanzwirksamen Volksbegehren und Volksentscheiden “114 verabschiedete sich der Verfassungsgerichtshof von der bisher entscheidenden „Erheblichkeitsschwelle“115 und beschränkte das neue Finanztabu durch eine zeitliche Zäsur: Unzulässig seien „danach nur Volksbegehren, die das Haushaltsgesetz und den in ihm festgestellten Haushaltsplan für das laufende Haushaltsjahr unmittelbar zum Gegenstand haben ... Dagegen erstreckt sich der Haushaltsvorbehalt des Art. 62 Abs. 2 VvB nicht auf finanzwirksame Gesetze, die sich lediglich auf künftige Haushaltsgesetze und zukünftige Haushaltsperioden auswirken."“116

\subsubsection{Die Änderung des Timings}

Das Timing des relativ straffen und starren Verfahrens der Volksgesetzgebung zu ändern wurde von Anfang der Reform an gefordert. PDS (2000) ${ }^{117}$ und Grüne (2005) schlugen beim Volksbegehren eine Verdoppelung der Eintragungsfrist von zwei auf vier Monate vor, weil der bisherige Zeitraum „zu knapp bemessen(e)“" sei ${ }^{118}$. Das Bündnis erhob 2006 in seinem Gesetzentwurf die gleiche Forderung ${ }^{119}$, obwohl man sich eigentlich sogar sechs Monate Zeit für die Eintragung wünschte ${ }^{120}$. Über eine Verfahrenserleichterung an dieser Stelle bestand alsbald grundsätzlicher Konsens ${ }^{121}$, und schon Mitte März hatte man sich auf die Verlängerung der Eintragungsfrist auf vier Monate verständigt. Dieses Reform-

113 Spitz wiesen die Richter darauf hin, aus der Entstehungsgeschichte ergebe sich mitnichten, daß der verfassungsändernde Gesetzgeber ,letztlich alles beim Alten belassen wollte“, LVerfGE 20, 45 (61).

114 Ebenda.

115 Zivier sah in dem alten Finanztabu unter jener extensiven Interpretation des Verfassungsgerichtshofs potentiell bloß einen „Taschengeldparagraphen“ (so E.R. Zivier, Verfassung und Verwaltung von Berlin, Berlin, 4. Aufl. 2008, S. 214), was vielsagend ausdrückt, daß sich die Abgeordneten des Volkes an dieser Stelle oft wie die gesetzlichen Vertreter eines Minderjährigen (vgl. § $110 \mathrm{BGB}$ ) gerieren.

116 LVerfGE 20, 45 (58). - Zustimmend F. Wittreck, in: JdD 2 (2010), S. 322 f. (323); M. Klatt, Die Zulässigkeit des finanzwirksamen Plebiszits, in: Der Staat 50 (2011), S. 3$44(33,44)$.

117 Drs. $14 / 655$ v. 14.9.2000, S. 2 (Art. I Nr. 3 [zu Art. 62 Abs. 1 S. 1]).

118 Drs. $15 / 4472$ v. 16.11.2005, Art. I Nr. 2 c (zu Art. 62 Abs. 5 [S. 1]) und Begründung dazu (S. 3).

119 Bündnis, Entwurf (Fn. 17), Nr. 4, Vorschlag zu Art. 62 Abs. 4 S. 1.

120 Berlin wird demokratischer (Fn. 12).

121 Vgl. Zawatka-Gerlach, Regierungschef (Fn. 92), in: Tsp. Nr. 19 079 v. 20.1.2006. 
stück (vgl. Art. 62 Abs. 4 VvB a.F., Art. 63 Abs. 1 S. 2 VvB n.F.) bedeutete nicht nur eine Verlangsamung des Verfahrens. Die Gewährung von mehr Zeit muß ja zusammengesehen werden mit der gleichzeitig beschlossenen Hürdensenkung von zehn auf sieben Prozent im Grundverfahren. Kombiniert man beide in dem sogenannten Mobilisierungskoeffizienten ${ }^{122}-$ dem Maß des auf den Betreibern eines plebiszitären Projekts in diesem Verfahrensstadium lastenden Qualifizierungsdrucks -, sank dieser von $0,167^{123}$ auf $0,058^{124}$. D.h. die den Initiatoren abverlangte Anstrengung wurde nicht nur halbiert - wie der bloße Blick auf die Monate nahelegen könnte -, sondern sie wurde auf fast ein Drittel ermä$\beta_{i g t}{ }^{125}$. Der Tonus des Verfahrens ließ deutlich nach; darauf ist noch einzugehen.

Der Gesetzentwurf des Bündnisses enthielt auch noch einen innovativen Vorschlag für die Ansetzung des Volksentscheids. Die bisherige rigide Frist von vier Monaten nach dem Zustandekommen eines Volksbegehrens (Art. 63 Abs. 1 S. 1 VvB a.F.) sollte auf bis zu acht Monate verlängert werden können, wenn dadurch „der Volksentscheid mit Wahlen oder anderen Volksentscheiden zusammengelegt werden kann “126. Diese Verlängerungsklausel nahm die interfraktionelle Arbeitsgruppe in den nächsten Wochen auf (vgl. Art. 62 Abs. 4 S. 2 VvB n.F.). Die All-Parteien-Vorlage begründete diese Flexibilisierung so, daß damit ,eine höhere Beteiligung erreicht werden“ könne und daß sie „dem gewünschten Aspekt Bürgerfreundlichkeit und auch der Notwendigkeit, kostenschonend zu verfahren“, entspreche ${ }^{127}$.

Im Bundesländer-Vergleich ${ }^{128}$ befindet sich Berlin nach der Reform weiterhin im Mittelfeld. Der auf den Initiatoren lastende Mobilisierungsdruck ist deutlich geringer als in jenen Ländern, in denen nur 14 Tage zur Verfügung stehen, um zehn Prozent (Bayern), 16,7 Prozent (Baden-Württemberg) oder gar 20 Prozent (Saarland) der Stimmberechtigten zur Eintragung zu bewegen. Vier Monate Zeit - wie nun Berlin - geben auch Brandenburg und Thüringen (bei freier Samm-

122 Der Mobilisierungskoeffizient besagt, welchen Prozentsatz der Stimmberechtigten die Betreiber eines plebiszitären Projekts durchschnittlich pro Tag zur Eintragung mobilisieren müssen, um am Ende der Eintragungsfrist die notwendige Unterstützung beisammen zu haben, vgl. Jung, Berlin (Fn. 51), S. 41 Fn. 111.

123 Zehn Prozent der Stimmberechtigten innerhalb von zwei Monaten (den Monat gerechnet zu 30 Tagen).

124 Sieben Prozent der Stimmberechtigten innerhalb von vier Monaten.

125 Bei dem Wunsch-Regelwerk des Bündnisses - 100.000 Unterschriften im Grundverfahren gleich 4,1 Prozent der Stimmberechtigten, zu sammeln innerhalb von sechs Monaten - wäre der Mobilisierungskoeffizient gar auf weniger als ein Siebtel gegenüber den bisher geltenden Anforderungen gesunken.

126 Bündnis, Entwurf (Fn. 17), Nr. 4, Vorschlag zu Art. 63 Abs. 1 S. 1.

127 Drs. $15 / 5038$ v. 26.4.2006, S. 6 f. (Begründung zu Art. 1 Nr. 8 [zu Art. 62 und 63 sowie zu Art. 62 Abs. 4]).

128 Vgl. Rehmet, Volksbegehrensbericht 2011 (Fn. 24), S. 10. 
lung), die eine deutlich niedrigere (Brandenburg: ca. 4,1 Prozent) oder eine höhere Hürde (Thüringen: zehn Prozent) aufstellen. Erheblich mehr Zeit gewähren den Initiativen Schleswig-Holstein, Sachsen und Sachsen-Anhalt - nämlich sechs Monate, innerhalb deren die Unterschriften von fünf, ca. zwölf bzw. elf Prozent der Stimmberechtigten gesammelt werden müssen - sowie Niedersachsen: zwölf Monate für zehn Prozent ${ }^{129}$. Wieder andere Zeitvorstellungen haben die Eidgenossen, die für (die funktional entsprechenden) Volksinitiativen auf Bundesebene 18 Monate Frist setzen ${ }^{130}$.

Eine Verlängerung der Frist, um die Volksbegehrenshürde zu überwinden, kommt den Initiatoren entgegen, die, um die praktische Mühe des Sammelns wissend, immer gerne mehr Zeit hätten. Daher wurde dieses Reformstück von den Verfechtern direkter Demokratie begrüßt, und damit haben sie auch theoretisch recht: Volksgesetzgebung ist grundsätzlich ein langsames Verfahren; hier wird nicht einfach ein fertig vorliegender Volkswille abgefragt, sondern ein politischer Wille des Volkes gebildet, was zugleich einen wichtigen gesellschaftlichen Lernprozeß darstellit ${ }^{131}$. Allerdings sind zwei Konsequenzen zu bedenken: Wenn für die Eintragungen beim Volksbegehren nur 14 Tage zur Verfügung stehen - wie in den drei aufgezählten Bundesländern, aber auch z.B. zur Weimarer Zeit auf Reichsebene -, folgt die Mobilisierung durch die Initiatoren dem Kampagnenprinzip $^{132}$. Dieses ist jedoch schon bei den zwei Monaten des alten Regelwerks nicht immer durchzuhalten; der „Spannungsbogen“ kann dann zusammenbrechen. Beim bis zu der Reform einzigen (durchgeführten) Volksbegehren in Berlin („Schluß mit der Rechtschreibreform!“”, 1999) war derartiges bereits zu

129 Nur Brandenburg (Art. 77 Abs. 3 S. 1), Sachsen (Art. 72 Abs. 2 S. 1 u. 2), SchleswigHolstein (Art. 42 Abs. 1 S. 5) und Thüringen (Art. 82 Abs. 5 S. 2) legen die Frist in der Verfassung fest. In den anderen aufgeführten Ländern ist dies dem Ausführungsgesetz überlassen.

130 Vgl. Linder, Demokratie (Fn. 25), S. 253 f., 273, und Art. 138 Abs. 1, 139 Abs. 1 BV 1999 i.d.F. v. 2009.

131 Vgl. Jung, Grundsatzfragen (Fn. 54), S. 330 f.

132 Dazu hatte Evers schon vor einem Vierteljahrhundert gewarnt, bezogen auf Volksentscheide: Diese „dürften in aller Regel das Ende der Sachdiskussionen sein. Je näher der Tag der Abstimmung naht, desto weniger werden die Debatten um sachliche Inhalte und desto mehr um Prozentpunkte kreisen. Grundsätzliche inhaltliche Fragen werden zwangsläufig einer Stimmenbeschaffungsarithmetik untergeordnet, gehaltvolle Differenzierungen zugunsten einer Ja-Nein-Logik eingeebnet.“ T. Evers, Mehr Demokratie durch Volksentscheid?, in: KritJ 19 (1986), S. 423-433 (428). Für Volksbegehren unter hohem Mobilisierungsdruck gilt das gleiche. Der Kommunikation und der öffentlichen Deliberation als den "Seelen der Direkten Demokratie“ (so A. Gross, Das Design der Direkten Demokratie und ihre Qualitäten. Erfahrungen und Reformideen im Vergleich zwischen Kalifornien, Schweiz und den deutschen Bundesländern, in: T. Schiller/V. Mittendorf [Hrsg.], Direkte Demokratie - Forschungsstand und Perspektiven, Wiesbaden 2002, S. 331-339 [336]) bekommt solcher Druck in keiner Phase des Verfahrens. 
beobachten ${ }^{133}$. Die Verdoppelung der Eintragungszeit erzwingt einen Wechsel des Mobilisierungskonzepts von der Kampagne zu einem graswurzel-demokratischen Vorgehen. Damit zusammen hängt als zweite Konsequenz der Übergang von der Amtseintragung zur sogenannten freien Sammlung, deren Zulassung das Bündnis zu Recht als „entscheidend“ bezeichnet hat, „damit Volksbegehren eine reelle Chance bekommen“"134. Die dazu 2006 zwischen den Parteien des Abgeordnetenhauses klar vereinbarte Reform des Ausführungsgesetzes kam schließlich erst fast zwei Jahre später zustande ${ }^{135}$.

Das durch die Verlängerungsklausel angestrebte Ziel, einen Volksentscheid wenn möglich ,gemeinsam mit Wahlen oder mit anderen Volksentscheiden durch(zuführen)“"(Art. 62 Abs. 4 S. 2 VvB n.F.), ist ein effizientes Mittel, um die Abstimmungsbeteiligung zu erhöhen. Der Huckepack-Effekt vor allem von Wahlen ist empirisch gut belegbar ${ }^{136}$ - dies sind die oben erwähnten statistischen „Ausreißer“ bei der direktdemokratischen Partizipation in Deutschland. Man könnte natürlich auch - etwas ketzerisch - fragen, ob damit das richtige Ziel gewählt ist. Mit Blick auf die Praxis in den US-Bundesstaaten wurde bemerkt, daß Beteiligung und Fernbleiben auch mit (dem subjektiven Gefühl von) Kompetenz bzw. Inkompetenz vor dem zur Abstimmung stehenden Problem zu tun haben ${ }^{137}$, und für die schweizerischen Verhältnisse hat z.B. C. Welzel aus der Kompetenzperspektive ausgeführt, daß sich an Volksentscheiden gerade diejenigen beteiligten, „die sich besonders betroffen fühlen und daher informierter und urteilssicherer sind. Aus der Perspektive einer funktional variierenden Kompetenzmobilisierung ist eine von Frage zu Frage unterschiedlich selektive Beteiligung sogar ausgesprochen wünschenswert“ - ausdrücklich bezogen auf Fälle von nur 30 oder

133 Vgl. Jung, Dreimal Fehlschlag (Fn. 13), S. 55. - In diesem Sinne empfahl Pestalozza, Auf gutem Weg (Fn. 33), S. 312, allerdings mit Blick auf die neueingeführte Verlängerungsoption nach einem erfolgreichen Volksbegehren, die Initiatoren sollten ,in aller Regel Wert auf eine zeitnahe Durchführung des Volksentscheides legen, um den Impetus des erfolgreichen Volksbegehrens in die letzte Phase eines ermattenden Verfahrens hinüberzuretten“.

134 Berlin wird demokratischer (Fn. 12).

135 Vgl. § 24 Abs. 3 AbstG i.d.F. des Art. I Nr. 24 d Gesetz zur Anpassung abstimmungsrechtlicher Vorschriften und begleitender Regelungen v. 20.2.2008, GVB1. S. 22. - Eine Übersicht über die verschiedenen Eintragungsverfahren in den Bundesländern gibt Rehmet, Volksbegehrensbericht 2011 (Fn. 24), S. 10.

136 Vgl. Jung, Quorenproblem (Fn. 82), S. 886-891; dens., ,Wahlbeteiligung runter, Bürgerbeteiligung rauf!" - Zu welcher Art von Partizipation führt mehr direkte Demokratie?, in: S. Frech/I. Juchler (Hrsg.), Bürger auf Abwegen? Politikdistanz und politische Bildung. Siegfried Schiele für seine Verdienste um die Didaktik politischer Bildung, Schwalbach/Ts. 2011, S. 51-80 (60-63).

137 Vgl. H.K. Heußner, Volksgesetzgebung in den USA und in Deutschland. Ein Vergleich der Normen, Funktionen, Probleme und Erfahrungen, Köln/Berlin/Bonn/München 1994 (Erlanger Juristische Abhandlungen Bd. 43), S. 414-418. 
40 Prozent Beteiligung ${ }^{138}$. Frank und frei gefragt: Fallen die Entscheidungen an den Urnen dadurch besser aus, daß auch Leute mitstimmen, die wegen der Wahlen „halt schon 'mal da“ sind, aber wegen des zur Entscheidung anstehenden Sachproblems als solchem sich nicht die Mühe machen würden, eigens zum Abstimmungslokal zu gehen? ${ }^{139}$ Aber diese Frage ist wohl zu theoretisch. Angesichts der derzeitigen politischen Kultur in Deutschland, wo die direkte Demokratie nicht nur um ihre Einführung und Durchsetzung noch zu kämpfen hat, sondern jeder Volksentscheid mit niedriger Beteiligung sich sofort dem Vorwurf mangelnder Legitimation ausgesetzt sieht, ist das Erreichen einer möglichst hohen Abstimmungsbeteiligung ein vorrangiges politisches Ziel. Wie Welzel kann man in der Zukunft argumentieren, wenn die direkte Demokratie in Deutschland fest etabliert ist und im Staatsleben bei diesen Fragen - ein Traum? - Gelassenheit herrscht.

\subsubsection{Die Einführung der sogenannten anderen Vorlage}

Nach den reformierten Regeln sind Volksbegehren und Volksentscheid nicht mehr nur über einen ausgearbeiteten Gesetzentwurf möglich (so Art. 62 Abs. 1 S. 3 VvB a.F.). Volksbegehren „können darüber hinaus darauf gerichtet werden, im Rahmen der Entscheidungszuständigkeiten des Abgeordnetenhauses zu Gegenständen der politischen Willensbildung, die Berlin betreffen, sonstige Beschlüsse zu fassen“ (Art. 62 Abs. 1 S. 2 VvB n.F.). Über den einem solchen Volksbegehren zugrunde liegenden Entwurf „eines sonstigen Beschlusses“ kann dann nach den allgemeinen Regeln des Grundverfahrens auch ein Volksentscheid stattfinden (vgl. Art. 62 Abs. 4 VvB n.F.).

Die Entstehungsgeschichte dieser Erweiterung ist wenig ergiebig. Die PDS plädierte 2000 dafür ${ }^{140}$. Der Entwurf der Grünen von 2005 sah noch nichts dergleichen vor ${ }^{141}$. Das Bündnis forderte zwar in seinem Gesetzentwurf 2006 die Einführung der sogenannten anderen Vorlage ${ }^{142}$, ließ sich aber in seiner weiteren Werbe- und Kritikarbeit während des Reformprozesses - soweit ersichtlich nicht mehr dazu aus. Die interfraktionelle Arbeitsgruppe griff den Punkt erst An-

138 Vgl. C. Welzel, Repräsentation alleine reicht nicht mehr. Sachabstimmungen in einer Theorie der interaktiven Demokratie, in: R. Schneider-Wilkes (Hrsg.), Demokratie in Gefahr? Zum Zustand der deutschen Republik, Münster 1997, S. 54-79 (64).

139 Harsch kritisiert Rux, Direkte Demokratie (Fn. 83), S. 776: „Manipulation der Beteiligungsquote“. Er stellt auch klar, daß ,eine möglichst hohe Abstimmungsbeteiligung keine Gewähr für die Richtigkeit des Abstimmungsergebnisses bietet“" (S. 901).

140 Drs. 14/655 v. 14.9.2000, S. 2 (Art. I Nr. 3 [zu Art. 62] und Nr. 4 [zu Art. 63]).

141 Drs. $15 / 4472$ v. 16.11.2005.

142 Bündnis, Entwurf (Fn. 17), Nr. 4, Vorschlag zu Art. 62, Nr. 5 bzw. zu Art. 63. 
fang April nachträglich - nach der grundlegenden Einigung - auf. Die Linkspartei.PDS soll dieses Reformdetail favorisiert haben. Auch als darüber eine Verständigung erzielt worden war, tat man sich damit auffallend schwer, sie zu begründen ${ }^{143}$. So wundert es nicht, daß während der Lesungen des Abgeordnetenhauses lediglich der Redner der Linkspartei.PDS diesen Reformpunkt ansprach, und dies in eigenartiger Weise: erst ein ironisches Understatement - „das finde ich auch nicht ganz irrelevant" - und dann ein großes Wort dazu, daß künftig „nahezu alles“, worüber dieses Parlament entscheiden könne, auch auf dem Wege der Volksinitiative, des Volksbegehrens und des Volksentscheids durchgesetzt werden könne: „Das ist in der Tat ein rapider Schritt nach vorn.“144

Die Beurteilung dieses Reformschritts ist schwierig. Historisch sei festgehalten, daß die Erweiterung der klassischen Volksgesetzgebung auf die Befassung des Parlaments mit „bestimmten Gegenständen der politischen Willensbildung“ bei der Schaffung einer neuen Verfassung in Schleswig-Holstein 1989 entwickelt wurde (vgl. Art. 41 f. Verf. SH). Doch während diese Neuerung auf der ersten Stufe des ebenfalls neuen dreistufigen Verfahrens (bei der Volksinitiative) viel Anklang fand - nicht weniger als zehn Bundesländer kennen heute dieses direktdemokratische Instrument -, zögerte man mit der Rezeption der sogenannten „anderen Vorlage“ für die zweite und dritte Verfahrensstufe (Volksbegehren und Volksentscheid) doch sehr. Nur Brandenburg 1992 und Hamburg 2001 ${ }^{145}$ übernahmen bisher die schleswig-holsteinische Innovation komplett (vgl. Art. 76 ff. BbgVerf., Art. 50 Abs. 1-3 Verf. HH).

Die Erfahrungen ${ }^{146}$ mit der neuen direktdemokratischen Partizipationsform waren bis vor kurzem gering. Zwar erfreute sich die sogenannte ,andere Vorlage" in Schleswig-Holstein und Brandenburg zunächst ausnehmender Beliebtheit. Ersichtlich wurde sie dabei in einem ähnlichen Sinne benutzt, wie das schweizerische Verfassungsrecht für das Initiativbegehren die Form der ,allgemeinen Anregung“ (neben der Form des ,,ausgearbeiteten Entwurfs“) bereithält. Die Initiatoren wählten jeweils eine auf den sachlichen Kern konzentrierte und dem Publikum besser vermittelbare Fassung ihres Anliegens und gaben dieser gegenüber einer rechtstechnisch ausgearbeiteten, aber damit für Nichtjuristen meist schwer

143 Die „Begründung“ der All-Parteien-Vorlage für den parlamentarischen Prozeß ist bloß eine Paraphrase der neuen Bestimmungen, vgl. Drs. 15/5038 v. 26.4.2006, S. 7 (Begründung zu Art. I Nr. 8 [zu Art. 62 Abs. 1]).

144 Abg. Lederer (Linkspartei.PDS), AH 4.5.2006, S. 7341 D.

145 Vgl. Klooß, Reform (Fn. 8, S. 98 f.

146 Grundsätzlich skeptisch - ohne Empirie - äußerte sich Pestalozza, Auf gutem Weg (Fn. 33), S. 301: „Die Idee, das Volk zu ermächtigen, alle, nicht nur die gesetzgeberischen Entscheidungen des Parlaments zu ersetzen, mag dem Perfektionisten gefallen; aber sie überschätzt wohl das Gewicht der nichtgesetzgeberischen Tätigkeit des Parlaments und ihre Attraktivität für das Volk, unterschätzt vielleicht auch das damit einhergehende Vertrauen, das die Bevölkerung dem ,sonstigen“ Tun des Parlaments entgegenbringt.“ 
verständlichen Vorlage den Vorzug. Die rechtsstaatlich unerläßliche Umsetzung einer eventuellen positiven Entscheidung wurde dabei offenkundig der Regierungs- bzw. Parlamentsbürokratie überlassen ${ }^{147}$. Doch während in SchleswigHolstein eine solche ,andere Vorlage“ in einem berühmten Fall („Buß- und Bettag") das Verfahren bis zum Volksentscheid 1997 durchlief $^{148}$, hatte in Brandenburg noch keine dieser Volksinitiativen auch nur auf der zweiten Verfahrensstufe des Volksbegehrens Erfolg - bis Ende 2012 ${ }^{149}$.

Anders kurz nach ihrer Einführung in Hamburg. Dort durchlief die Volksinitiative „Gesundheit ist keine Ware“ 2002-2004 das vollständige Grundverfahren der Volksgesetzgebung und schloß mit einem Volksentscheid ab, bei dem 76,8 Prozent der abgegebenen gültigen Stimmen die Vorlage bejahten ${ }^{150}$. Damit war folgender Text beschlossen: „Der Senat wird aufgefordert, sicherzustellen, dass die Freie und Hansestadt Hamburg Mehrheitseigentümerin des Landesbetriebs Krankenhäuser (LBK), seiner einzelnen Krankenhäuser und anderen Einrichtungen bleibt“". So war natürlich bei den Initiatoren die Enttäuschung groß, als ihnen das Hamburgische Verfassungsgericht binnen zehn Monaten den staatsrechtlichen Wert ihrer Bemühungen bescheinigte: „Ein Volksentscheid, der auf eine ,Aufforderung' an den Senat gerichtet ist, entspricht dem parlamentarischen ,Ersuchen'. Beides besitzt keine rechtliche Verbindlichkeit für den Senat.“ Nur einen schwachen Trost bedeutete die weitere Ausführung, der Grundsatz der Organtreue verlange, „daß das Parlament nicht leichtfertig über den im Volksentscheid zum Ausdruck gekommenen Willen des Volkes hinweggehen darf, son-

147 Vgl. Jung, Abschluß (Fn. 5), S. 79 Fn. 266.

148 Vgl. A. Schimmer, „Ihre Stimme für den Bußtag, weil Feiertage unbezahlbar sind“ - Der Kampf der Nordelbischen Kirche für die Erhaltung des Buß- und Bettages, in: Heußner/Jung, Mehr direkte Demokratie (Fn. 38), S. 269-286 (272). - Abgestimmt wurde über folgende Vorlage: ,Ich fordere den Schleswig-Holsteinischen Landtag auf, das Feiertagsgesetz so zu ändern, daß der Buß- und Bettag wieder gesetzlicher Feiertag wird." StatLA Schleswig-Holstein, Stat. Ber. B VII 4-5/97, S. 1.

149 Siehe F. Rehmet/T. Weber/L. Gogolin, [Drittes] Volksentscheids-Ranking 2010, hrsg. v. Mehr Demokratie e.V., Berlin 2010, S. 39. - Das heißt freilich nicht, daß diese Vorstöße allesamt vergeblich gewesen wären. Eine realistische Einschätzung für Brandenburg geht dahin, „daß so gut wie jede Volksinitiative in gewisser Weise einen Erfolg bedeutet und sich eine Volksinitiative eigentlich immer lohnt", und sei es nur in Form positiver politischer Fernwirkungen im Sinne der Initiatoren, vgl. Jung, Gesetzgebung (Fn. 7), S. 85. Die „eher subtile Wirkung der Möglichkeit direkter Demokratie“ darf nicht durch eine Orientierung an einem simplen Erfolgs-/Mißerfolgs-Raster ausgeblendet werden, so schon ders., Die Praxis direkter Demokratie unter den neuen Landesverfassungen, in: ZG 13 (1998), S. 295-328 (328).

150 Vgl. O. Jung, Volksgesetze und parlamentarische Konterlegislatur, in: K.H. Schrenk/M. Soldner (Hrsg.), Analyse demokratischer Regierungssysteme. Festschrift für Wolfgang Ismayr zum 65. Geburtstag, Wiesbaden 2010, S. 427-442 (429). 
dern diesen würdigen und danach seine Abwägung vornehmen muß“151. Ungeachtet aller politischen Behauptungen, das Volk habe entschieden, daß der LBK nicht privatisiert werden dürfe, und Verfassungsorgane seien an den Volksentscheid gebunden, und des nicht minder politischen Vorwurfs „Senat ignoriert Volksentscheid“" war damit juristisch nichts mehr zu deuteln: Per Volksentscheid war hier kein Gesetz im Sinne eines für alle verbindlichen Gebotes oder Verbotes beschlossen worden, sondern die zitierte Aufforderung an den Senat. Gewiß war dieser Volksentscheid auch verbindlich, aber diese Verbindlichkeit beschränkte sich nach dem gewählten Verfahren darauf, daß sich der Senat mit dem LBK-Problem noch einmal befassen mußte; eine weitergehende Bindung dergestalt, daß der Senat als Frucht seiner Befassung auch zu einem bestimmten Ergebnis kommen müßte, bestand ersichtlich nicht ${ }^{152}$. So zeigte dieser Fall die besondere Problematik des dreistufigen Verfahrenswegs für eine ,andere Vorlage“:

$\mathrm{Zu}$ hinterfragen ist, warum die Initiatoren mit der „Aufforderung an den Senat" die Form der anderen Vorlage gewählt haben und 593.497 Bürger mit Ja abstimmen ließen - wohl wissend (davon kann man ausgehen), daß sie damit letztlich einen Punkt auf der Tagesordnung des Senats erzwingen würden ${ }^{153}$.

$\mathrm{Zu}$ fragen ist, warum die Initiatoren nicht einen ausgearbeiteten und begründeten Gesetzentwurf vorgelegt haben und durch Volksentscheid verabschieden ließen. Dann könnte zwar - jedenfalls nach der (noch) herrschenden Meinung ${ }^{154}$ die Bürgerschaft das entsprechende Volksgesetz wieder aufheben, aber das würde ihr gewiß politisch schwerfallen ${ }^{155}$.

151 HambVerfG, Urteil v. 15.12.2004, LVerfGE 15, 221 (221: Ls. 2 b und d); siehe dazu H.P. Bull, Der Volksentscheid: unverbindlich und folgenlos? Anmerkungen zum Urteil des Hamburgischen Verfassungsgerichts im LBK-Streit, in: NordÖR 2005, S. 99-101.

152 Ein Verstoß gegen die Verfassung und eine Mißachtung des Volksentscheids hätten also nur dann vorgelegen, wenn sich der Senat geweigert hätte, das Thema Privatisierung des LBKs überhaupt noch einmal zu behandeln. Dies war nicht der Fall.

153 Dabei wurden die Initiatoren noch während des direktdemokratischen Verfahrens gewarnt, als das Hamburgische Verfassungsgericht in einem Eilverfahren bemerkte, daß „sogar ein erfolgreicher Volksentscheid mit dem beantragten Text für den Senat nicht verbindlich wäre“ (HambVerfG, Urteil v. 15.12.2003, LVerfGE 14, 246 [253]). Schon während des laufenden Eilverfahrens - ohne dessen Ausgang abzuwarten - stellten die Vertreter der Volksinitiative den Antrag auf Durchführung des Volksentscheids. - Engelken bezweifelt denn auch mit Recht, daß in diesem Fall das Begehren ,sachgerecht" formuliert wurde, vgl. K. Engelken, Kann ein Volksbegehren Sperrwirkung für Gesetzgebung und Regierung haben? - Folgen von Verfassungsänderungen und freiem Unterschriftensammeln - Zugleich Besprechung der Urteile des Hamburgischen Verfassungsgerichts vom 15. Dezember 2003 und 15. Dezember 2004 -, in: DVB1. 2005, S. 415-423 (419).

154 Entsprechend auch HambVerfG, Urteil v. 17.12.2004, in: NordÖR 2005, S. 109 (Ls. 2 c).

155 Die Probe aufs Exempel lieferte die Hansestadt zwei Jahre später, als die Bürgerschaft das durch Volksentscheid beschlossene Gesetz zur Änderung des Gesetzes über die Wahl 
Geradezu als „falsches Spiel“ jedoch muß es bezeichnet werden, wenn man das eine rechtliche Verfahren - die „Aufforderung“ in Form der ,anderen Vorlage" - wählt, aber aus dem beeindruckenden politischen Abstimmungserfolg dann eine Verbindlichkeit in der Sache herausdestillieren will, die rechtlich nur in dem anderen Verfahren - der Volksgesetzgebung im eigentlichen Sinne - zu erreichen ist.

Die berlinischen Erfahrungen mit dieser Partizipationsform beschränken sich bislang auf den Fall „Tempelhof“, der 2008 mit einem Volksentscheid abgeschlossen wurde. Die Initiatoren errangen einen beeindruckenden Sieg an den Urnen (60,3 Prozent der abgegebenen gültigen Stimmen lauteten auf „Ja“), aber ihr Vorhaben scheiterte „unecht“" an dem 25prozentigen Zustimmungsquorum (erreicht wurden nur 21,7 Prozent). Hervorzuheben ist, daß für das Anliegen „Tempelhof bleibt Verkehrsflughafen“ kein Volksgesetzgebungsverfahren im strengen Sinne zulässig war; gegen die Flughafenschließung als Verwaltungsentscheidung konnte man nur im Wege der „anderen Vorlage“ angehen ${ }^{156}$.

Vor diesem Hintergrund verwundert ein Verdikt von Efler, dessen Wort nach seiner Rolle bei der Reform der direkten Demokratie in Berlin 2006 Gewicht hat und der für die Bundesebene inzwischen von der Einführung einer, ,anderen Vorlage“ verfassungspolitisch abrät. Denn: „In Berlin und Hamburg sind die Erfahrungen damit eher negativ. Entsprechende Volksentscheide waren rechtlich un-

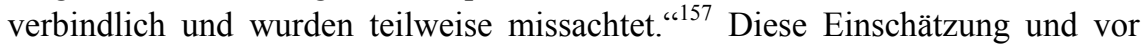
allem ihre Begründung fordern zum Widerspruch heraus. Der erste Grund ist unhaltbar. Die schwache rechtliche Verbindlichkeit dieser Partizipationsform war juristisch von vornherein klar und vom Hamburgischen Verfassungsgericht bereits 2003 und 2004 eindeutig festgestellt worden, als die Reformer in Berlin im April 2006 beschlossen, die ,andere Vorlage“ zu übernehmen. Nun kann dies nicht fünf Jahre später als Argument gegen diese Institution ins Feld geführt

zur hamburgischen Bürgerschaft, des Gesetzes über die Wahl zu den Bezirksversammlungen, des Bezirksverwaltungsgesetzes und des Hamburgischen Meldegesetzes v. 5.7.2004 (GVB1. S. 313) in den politisch zentralen Punkten aufhob - ohne daß es einmal praktisch angewandt worden wäre, vgl. Gesetz zur Änderung des Gesetzes über die Wahl zur hamburgischen Bürgerschaft, des Gesetzes über die Wahl zu den Bezirksversammlungen und des Bezirksverwaltungsgesetzes v. 19.10.2006, GVB1. S. 519.

156 Vgl. Efler/Posselt, Demokratie (Fn. 21), S. 291. - Abgestimmt wurde über folgenden Beschluß: „Der Stadtflughafen Tempelhof ergänzt und entlastet den Verkehrsflughafen Berlin-Brandenburg International (BBI). Der Berliner Senat wird aufgefordert, sofort die Schließungsabsichten aufzugeben und den Widerruf der Betriebsgenehmigung aufzuheben. Tempelhof muss Verkehrsflughafen bleiben!“ Der Landesabstimmungsleiter (Hrsg.), Volksentscheid „Tempelhof bleibt Verkehrsflughafen!“ am 27. April 2008, Endgültiges Ergebnis, Stat. Ber. B VII 4-1, S. 1.

157 M. Efler, Nur wer sich verändert, bleibt sich treu, in: md magazin. zfdd 23 (2011), H. 3 [Nr. 90], S. 4-7 (6). 
werden. Der zweite Grund zielt auf den LBK-Fall in Hamburg, in dem man - bei aller formalen Korrektheit des Senatshandelns - cum grano salis von einer Mißachtung des Volkswillens sprechen könnte. Doch für ein ausgewogenes Urteil ist zunächst auch der Fall „Buß- und Bettag“ in Schleswig-Holstein heranzuziehen, und endlich ist für Hamburg noch der Schul-Volksentscheid 2010 zu betrachten, bei dem sich eine Volksinitiative („Wir wollen lernen!“) ebenfalls dieser Form der ,anderen Vorlage“ bediente ${ }^{158}$ - man sollte vor solch einem wichtigen Kurswechsel das vorhandene empirische Material vollständig auswerten.

Diese vier Fälle lehren ${ }^{159}$ :

158 Abgestimmt wurde über die Vorlage der Volksinitiative „Wir wollen lernen!“ - für den Erhalt des Elternwahlrechts in Klasse 4 und der weiterführenden Schulen ab Klasse 5: „Ich fordere die Bürgerschaft und den Senat der Freien und Hansestadt Hamburg auf, eine Ausgliederung der Klassen 5 und 6 aus den Gymnasien und anderen weiterführenden Schulen und deren Anbindung an die Grundschulen als ,Primarschulen` zu unterlassen.

Denn ich bin dafür, dass die Hamburger Gymnasien und weiterführenden Schulen in der bisherigen Form, d. h. beginnend mit der Unterstufe ab Klasse 5, erhalten bleiben und die Eltern auch in Zukunft das Recht behalten, die Schulform für ihre Kinder nach der Klasse 4 zu wählen.

Ich fordere deshalb Senat und Bürgerschaft auf, das Zwölfte Gesetz zur Änderung des Hamburgischen Schulgesetzes vom 20. Oktober 2009 (HmbGVB1. S. 373) zu diesen beiden Punkten unverzüglich rückgängig zu machen."(Nach dem Stimmzettel).

Die (Konkurrenz-)Vorlage der Bürgerschaft kann in diesem Zusammenhang außer Betracht bleiben.

159 Ein Einwand gegen die Vergleichbarkeit findet sich bei Pestalozza, Auf gutem Weg (Fn. 33), S. 302, der darauf hinweist, daß Berlin wie Schleswig-Holstein (Art. 41 Abs. 1 S. 1 Verf.) fordert, daß sich die „andere Vorlage“ „im Rahmen der Entscheidungszuständigkeit des Abgeordnetenhauses" (Art. 62 Abs. 1 S. 2 - Hervorhebung nicht i.O.) hält. Brandenburg hingegen verlangt nur die ,Zuständigkeit“ des Landtags (Art. 76 Abs. 1 S. 1 Verf.), und Hamburg formuliert die Landeszuständigkeit als selbstverständliche Voraussetzung gar nicht ausdrücklich (vgl. Art. 50 Abs. 1 S. 1 Verf.). Bei der engen Auslegung, die Pestalozza daher für geboten hält, „um Nichtentscheidungen - wie Empfehlungen, Ersuchen, Loyalitätsbekundungen, Proteste etc. -, für die ein Parlament auch zuständig ist, aus der Volkskompetenz auszuklammern“, hätte das Volksbegehren im Fall „Tempelhof" gar nicht zugelassen werden dürfen (so ausdrücklich a.a.O., S. 302 f.; ders., Einführung, in: Verfassungen der deutschen Bundesländer mit dem Grundgesetz, München, 9. Aufl. 2009, S. XV-CXXIII [LIII Fn. 4]). Indes stellte sich der Senat in diesem ersten praktischen Anwendungsfall auf den Standpunkt, zu den sonstigen Beschlüssen, „die das Abgeordnetenhaus im Rahmen seiner Entscheidungszuständigkeiten [hier irrig im Plural zitiert] zu Gegenständen der politischen Willensbildung fassen“ könne, gehörten ,auch politische Resolutionen ... Das Volksbegehren zielt darauf ab, den Flughafen Tempelhof als Verkehrsflughafen offen zu halten. Es liegt im Rahmen der Entscheidungszuständigkeit des Abgeordnetenhauses, einen derartigen Appell an den Senat zu richten." AH Drs. 16/0524 v. 14.5.2007, S. 1. - Auch Zivier, Verfassung (Fn. 115), S. 216 f., meint, daß der Senat hier das Erfordernis der Entscheidungskompetenz ,großzügiger interpretiert“ habe, als es rechtens sei, sieht freilich darin zutreffend einen „Präzedenzfall“, über den der Senat sich in künftigen Fällen schwer hinwegsetzen könne. 
In den Fällen „Buß- und Bettag“ in Schleswig-Holstein 1997 und „Tempelhof" in Berlin 2008 scheiterten die Initiatoren - trotz ihres Sieges an den Urnen „unecht“ an dem jeweils 25prozentigen Zustimmungsquorum. Dies ist geradezu ein deutsches „Normalschicksal“ und passiert im eigentlichen Volksgesetzgebungsverfahren mit ausgearbeiteten Entwürfen genauso.

Die Mißachtung des Volkswillens wie im LBK-Fall kann auch einem Volksgesetz widerfahren, wie der Fall „Rechtschreibreform“ in Schleswig-Holstein 2009 schlagend beweist ${ }^{160}$.

Beim Schul-Volksentscheid in Hamburg 2010 schließlich setzte sich eine Initiative ,von unten“ gegen eine offenkundig mißratene Reform durch, die zuletzt von allen in der Bürgerschaft vertretenen Parteien gestützt worden war $^{161}$. Ein größerer demokratiepolitischer Erfolg (um den Streit pädagogischer Konzepte geht es hier nicht) ist gar nicht vorstellbar.

Als spezifischer Berliner Punkt ist noch anzuführen, daß 2007/08 nur durch eine ,andere Vorlage“ die Schließung des Flughafens Tempelhof in einem förmlichen direktdemokratischen Verfahren thematisiert werden konnte.

Wägt man diese vier Gesichtspunkte gegeneinander ab, erscheint die Bilanz der anderen Vorlagen bisher insgesamt positiv. Efler hat hier zu schnell „den Stab gebrochen“.

\subsubsection{Was nicht reformiert wurde}

$\mathrm{Zu}$ einem ausgewogenen Urteil über diese Reform insgesamt gehören nicht nur eine Analyse und Bewertung der einzelnen Reformschritte; in Rechnung zu stellen sind auch jene Problembereiche, in denen die Reformer jedenfalls im Ergebnis nichts änderten.

Zwei gewissermaßen immanente Problemfelder, die für eine Verbesserung der Volksgesetzgebung eigentlich hätten „beackert“ werden müssen, sind die Information und die Kosten. Volksgesetzgebung geschieht nicht von selbst. Es bedarf der Initiatoren, die das Verfahren in Gang setzen; diese sind auf Mitstreiter an-

160 Vgl. O. Jung, „Die rebellierende Vertretung“ (H. Nawiasky). Darf das Parlament ein vom Volk beschlossenes Gesetz (ohne weiteres) kassieren? Zum Vorgehen des SchleswigHolsteinischen Landtags im September 1999 (Fall „Rechtschreibreform“), in: A. Bovenschulte/H. Grub/F.A. Löhr/M. v. Schwanenflügel/W. Wietschel (Hrsg.), Demokratie und Selbstverwaltung in Europa. Festschrift für Dian Schefold zum 65. Geburtstag, BadenBaden 2001, S. 145-168 (146-150). - Siehe ferner den oben erwähnten Fall des volksbeschlossenen Wahlgesetzes in Hamburg 2004.

161 Vgl. O. Jung, Der Hamburger Volksentscheid über die Primarschule am 18. Juli 2010, in: md magazin. zfdd 22 (2010), H. 3 [Nr. 87], S. 10-15; dens., „Gucci-Protest oder Aufstand der Bürger?" unter http://www.mehr-demokratie.de/schule-volksentscheid-hamburg.html (Zugriff 22.3.2012). 
gewiesen, um die nötige massendemokratische Mobilisierung zu schaffen, und am Schluß - vor dem Volksentscheid - ist unter modernen Bedingungen einfach Werbung für die vorgeschlagene (Rechts-)Änderung erforderlich. Gleichwohl ist es sinnvoll, nicht alles der Initiative Privater zu überlassen, vor allem nicht bei der letzten Verfahrensetappe, wo das abstimmende Volk schließlich organschaftlich handelt und am Ende, bei Erfüllung aller Bedingungen, ein für alle verbindliches Gesetz herauskommt. Neben der Werbung, welche die Aktivisten für ihre Sache machen, ist dann auch die Information und Aufklärung durch den Staat angemessen. Die schweizerische Direktdemokratie kennt hierzu das „Abstimmungsbüchlein“, und in den US-Bundesstaaten gibt es „Voter Information Pamphlets “162. Unter den Bundesländern hat - auf der Verfassungsebene - Bayern nach eidgenössischem Vorbild bestimmt, daß jeder dem Volk zur Entscheidung vorgelegte Gesetzentwurf mit einer - das ist sprachlich etwas veraltet „Weisung“ der Staatsregierung zu begleiten ist, „die bündig und sachlich sowohl die Begründung der Antragsteller wie die Auffassung der Staatsregierung über den Gegenstand darlegen soll“ (Art. 74 Abs. 7 BayVerf.). Die Verfassung des Saarlandes hat diese Vorschrift übernommen (Art. 100 Abs. 2 S. 1 SaarlVerf.). Hingegen untersagt die ansonsten in mancher Hinsicht wegweisende Reformverfassung Schleswig-Holsteins von 1989 der Landesregierung bei der Veröffentlichung des zum Volksentscheid stehenden Gesetzentwurfs oder der anderen Vorlage ausdrücklich jede Stellungnahme (Art. 42 Abs. 3 S. 1 SHVerf.) - die Umkehrung des Diskursprinzips bei der Volksgesetzgebung ${ }^{163}$.

Die PDS hat zu diesem Problembereich 2000 eine Klausel vorgeschlagen, wonach ,eine ausgewogene Information der Öffentlichkeit über den Inhalt der den Volksbegehren und Volksentscheiden zugrunde liegenden Vorlagen“ zu „gewährleisten“ sei. Dies sei unerläßlich - begründete sie -, „damit die Bürgerinnen und Bürger ausreichend Gelegenheit zur Information und zur Meinungsbildung haben“"164. Die Grünen begnügten sich 2005 - nach brandenburgischem Vorbild (vgl. Art. 78 Abs. 1 S. 3 Bbg.Verf.) - mit der Forderung nach einer Veröffentlichung der zu Abstimmung stehenden Vorlagen ,in angemessener Form“. Auch damit sollte zwar „eine informierte Öffentlichkeit“ gewährleistet wer$\operatorname{den}^{165}$, doch ist eine solche Publikation des Textes, über den abgestimmt werden soll, nebst seiner Begründung eigentlich nur eine Selbstverständlichkeit und deutlich weniger als das Prinzip des Diskurses bei der Volksgesetzgebung, wie

162 Vgl. Heußner, Volksgesetzgebung (Fn. 137), S. 318-321.

163 Vgl. Jung, Entwicklungstendenzen (Fn. 73), S. 38. Siehe auch Heußner, Volksgesetzgebung (Fn. 137), S. 322 (,unverständlich“).

164 Drs. 14/655 v. 14. 9. 2000, S. 2 (Art. I Nr. 4 [zu Art. 63 Abs. 6 S. 1]), S. 4 (Begründung zu Art. 63 Abs. 6 S. 1).

165 Drs. $15 / 4472$ v. 16. 11. 2005, S. 2 (Art. I Nr. 3 a [zu Art. 63 Abs. 1 S. 3]), S. 3 (Begründung zu Art. I Nr. 3 [zu Art. 63 Abs. 1 S. 3]). 
es Bayern und das Saarland ansatzweise zu verwirklichen versuchen ${ }^{166}$. Der Gesetzentwurf des Bündnisses von 2006 endlich formulierte - im Artikel über den Volksentscheid - die Klausel, daß die Öffentlichkeit „über Inhalt und Durchführung des Volksbegehrens ausgewogen zu informieren“ "sei ${ }^{167}$. Besonders vor dem Volksentscheid - hieß es weiter - sei ,eine ausgewogene Information der Öffentlichkeit“ zu gewährleisten. Alle Stimmberechtigten erhielten ein „Abstimmungsheft" ${ }^{\text {"168. }}$.

In der von der interfraktionellen Arbeitsgemeinschaft vereinbarten und vom Abgeordnetenhaus beschlossenen Reform findet sich zum Thema „Information“ nichts. Es ist auch nicht bekannt, warum das Problem nicht ,angepackt“ wurde. Praktisch wurde dann 2008 eine Lösung gefunden auf der Ebene des Ausführungsgesetzes, womit sich Berlin nun in der Gesellschaft von Thüringen, Hamburg und Bremen befindet ${ }^{169}$. 332 Abs. 4 BlnAbstG 1997 (Stand 8.7.2010) legt das Prinzip des gleichen Umfangs der Pro- und Contra-Argumentation fest ${ }^{170}$.

„Volksgesetzgebung ist kein Privatvergnügen und sollte auch nicht als solches behandelt werden. Die Kontrolle bzw. Korrektur parlamentarischer Entscheidungen dient nicht weniger dem Gemeinwohl als die Arbeit der zu kontrollierenden bzw. zu korrigierenden Volksvertretungen selbst. In einer politischen Kultur, in der (was jetzt nicht hinterfragt werden soll) Parteien- und Fraktionsfinanzierung, Wahlkampfkostenerstattung und dergleichen mehr selbstverständlich sind, erscheint eine öffentliche Hilfe zumindest bei den Abstimmungskampfkosten ein Gebot der Gerechtigkeit.“' ${ }^{171}$ Schließlich stehen bei einem Volksentscheid der Initiative und ihrem Projekt mit der Regierung und der bzw. den sie tragenden Fraktion(en) zwei staatsfinanzierte Institutionen der repräsentativen Demokratie gegenüber, so daß auch das Gebot der Chancengleichheit zu beachten ist ${ }^{172}$. Insofern erstaunt es doch, daß nur sechs der 16 Bundesländer entsprechende Kos-

166 Vgl. O. Jung, Welche Regeln empfehlen sich bei der Einführung von Volksbegehren und Volksentscheid (Volksgesetzgebung) auf Bundesebene?, in: Evangelische Akademie Hofgeismar/Stiftung Mitarbeit (Hrsg.), Direkte Demokratie in Deutschland. Handreichungen zur Verfassungsdiskussion in Bund und Ländern. Mit Entwürfen zur Einführung von Volksbegehren und Volksentscheid auf Bundesebene („Hofgeismarer Entwurf“), Bonn 1991 (Brennpunkt-Dokumentation Nr. 12), S. 19-59 (34 ff.).

167 Bündnis, Entwurf (Fn. 17), Nr. 5 (zu Art. 63 Abs. 3).

168 Bündnis, Demokratie (Fn. 17).

169 Siehe Rehmet/Weber/Gogolin, Volksentscheids-Ranking 2010 (Fn. 149), S. 19.

$170 \S 19$ Abs. 2 HmbVAbstG 1996 (Stand: 16.12.2008) und § 2 Abs. 3 BremVolksentG 1996 (Stand 30.4.2012) schreiben darüber hinaus für den Fall, daß die Parlamente nicht als Ganze, sondern nach Fraktionen getrennt Stellung nehmen, die Platzverteilung im Informationsheft entsprechend der Sitzverteilung vor.

171 Jung, Grundsatzfragen (Fn. 54), S. 332.

172 Vgl. Weixner, Demokratie (Fn. 15), S. 176. 
tenerstattungsregelungen getroffen haben: Hamburg, Niedersachsen, Sachsen, Sachsen-Anhalt, Schleswig-Holstein und Thüringen ${ }^{173}$.

Die PDS schlug zu diesem Problem 2000 - im Anschluß an die Klausel über die Gewährleistung einer ausgewogenen Information - vor, daß die Träger eines Volksbegehrens „Anspruch auf Erstattung der Kosten einer angemessenen Information der Öffentlichkeit" haben sollten. Zur Begründung hieß es, dieser Kostenerstattungsanspruch sei nötig, damit die Träger eines Volksbegehrens „unabhängig von ihren wirtschaftlichen Möglichkeiten“ die Bürgerinnen und Bürger in ihrem Sinne informieren könnten ${ }^{174}$. Die Grünen griffen das Problem in ihrem Gesetzentwurf 2005 nicht auf. Der Gesetzentwurf des Bündnisses formulierte 2006 zu diesem Punkt eine interessante Doppelklausel: Im Ausführungsgesetz sei auch „der Anspruch auf Erstattung der notwendigen Kosten für die Organisation des Volksbegehrens und eines angemessenen Abstimmungskampfes“ zu regeln ${ }^{175}$. Für den ersten Tatbestand - also die zweite Verfahrensetappe - erläuterte die Begründung unmißverständlich: „Bei einem erfolgreichen Volksbegehren haben die Initiatorinnen und Initiatoren das Recht auf Kostenrückerstattung. “ 176

Auch für das Thema „Kosten“ unterblieb indes eine Regelung bei der Reform. Man visierte statt dessen wie bei der „Information“ eine Lösung im Ausführungsgesetz an. Im Herbst 2007 hatten sich die fünf Parteien des Abgeordnetenhauses bereits grundsätzlich auf eine begrenzte Kostenerstattung bei erfolgreichen Volksbegehren verständigt. Am 28. November 2007 hörte der Rechtsausschuß Sachverständige an. Der vorbereitende Fragenkatalog, den die Fraktionen untereinander abgestimmt hatten, ließ freilich schon Ungutes ahnen ${ }^{177}$. Gehört

173 Siehe Rehmet/Weber/Gogolin, Volksentscheids-Ranking 2010 (Fn. 149), S. 19. - Die Regelungen für diese Länder - sowie einige kleinere Erstattungsmöglichkeiten - sind tabellarisch aufgeführt bei R. Magin/C. Eder, Direkte Demokratie in den Bundesländern: Grundlagen, Institutionen, Anwendungen, in: M. Freitag/U. Wagschal (Hrsg.), Direkte Demokratie. Bestandsaufnahmen und Wirkungen im internationalen Vergleich, Berlin 2007 (Policy-Forschung und Vergleichende Regierungslehre Bd. 3), S. 151-187 (171). Grundsätzliche Überlegungen finden sich bei Jung, Welche Regeln (Fn. 166), S. 51-56, empirische Daten bei dems., Grundsatzfragen (Fn. 54), S. $332 \mathrm{f}$.

174 Drs. 14/655 v. 14. 9. 2000, S. 2 (Art. I Nr. 4 [zu Art. 63 Abs. 6 S. 2]), S. 4 (Begründung zu Art. 63 Abs. 6 S. 2).

175 Bündnis, Entwurf (Fn. 17), Nr. 5 (zu Art. 63 Abs. 4).

176 Bündnis, Demokratie (Fn. 17).

177 „Was spricht für eine Kostenerstattung? Wie kann eine angemessene Höhe der Kostenerstattung festgelegt werden? Regelungen in anderen Bundesländern? Ist es zulässig, die Kostenerstattung an den Erfolg eines Volksbegehrens zu knüpfen? Wenn nicht, nach welchem Maßstab müssen Kosten erstattet werden? Wie kann verhindert werden, dass diese Kostenerstattung zu einer Finanzquelle für radikale Gruppen (z.B. NPD) wird?““ Anlage zum Einladungsschreiben des Vorsitzenden des Ausschusses für Verfassungsund Rechtsangelegenheiten, Immunität und Geschäftsordnung an den Verfasser v. 12.11.2007. 
wurden der Verfasser, Dr. Michael Efler (Mehr Demokratie e.V.), Rechtsanwalt Dr. Christoph Lehmann, Vorsitzender der Initiative „Pro Reli“, und Rechtsanwalt Dr. Peter Neumann (Institut für sachunmittelbare Demokratie e.V., Dresden). Die Expertenrunde argumentierte, ,dass auch kleine Gruppierungen jenseits großer Verbände und Parteien die Möglichkeit haben müssten, ihr Anliegen mittels eines Volksbegehrens zu lancieren. Auf eine Höhe einigte man sich nicht, aber es war klar, dass die Kostenerstattung nie die kompletten Kosten erreichen würde, sondern bestenfalls eine Aufwandsentschädigung darstellen würde.“" ${ }^{\text {178 }}$

Doch dann scheiterte die Kostenerstattung doch noch auf eine denkwürdige Weise. Bis zur nächsten Sitzung des Rechtsausschusses hatten die rechtspolitischen Sprecher der Fraktionen - im Rahmen der Novellierung des gesamten Ausführungsgesetzes - folgende Finanzregelung als Kompromiß vereinbart: Für jede rechtswirksame Unterschrift beim Volksbegehren sollten die Initiatoren 0,15 Euro und für jede Ja-Stimme beim Volksentscheid 0,075 Euro bekommen, jeweils ,gedeckelt“ durch die Klausel, daß nur die verfahrensmäßig erforderlichen Mindestunterschriften bzw. -stimmen berücksichtigt würden ${ }^{179}$. Man hatte hier das Thüringer Erstattungsmodell übernommen ${ }^{180}$, das sich im Ländervergleich eher moderat, um nicht zu sagen: modest, ausnimmt. Sachsen-Anhalt z. B. gewährt mit 0,26 Euro pro Unterschrift bzw. Ja-Stimme fast den doppelten bzw. vierfachen Satz, ebenso Schleswig-Holstein mit 0,28 Euro pro Ja-Stimme ${ }^{181}$. Dennoch mußte der rechtspolitische Sprecher der SPD bei der Ausschußsitzung am 16. Januar 2008 einen Vorbehalt anmelden; es bestehe noch „Rückkoppelungsbedarf“ mit der Fraktion. So wurde das Thema vertagt ${ }^{182}$. Dem Vernehmen nach empfanden es Teile der Fraktion als ungerecht, daß nur die Befürworter ei-

178 So der zusammenfassende Bericht von O. Wiedmann, Anhörung zum Volksabstimmungsgesetz, http://besseres-wahlrecht-in-berlin.mehr-demokratie.de/2726.html?\&tx_t tnews[poin-ter] $=4 \&$ tx_ttnews[backPid] $=922 \&$ tx_ttnews[tt_news] $=1348 \& \mathrm{cHash}=\mathrm{cbc} 7 \mathrm{~b}$ cbbe709d69c48fd6b9ae49dd4ac (Zugriff 24.1.2008); vgl. AH Wortprotokoll Recht 16/19. - Die ausgearbeitete Stellungnahme des Verfassers v. 26.11.2007: „Welche Regelungen empfehlen sich für das neue Gesetz über Volksinitiative, Volksbegehren und Volksentscheid (Abstimmungsgesetz - AbstG)?" siehe unter www.parlament-berlin.de/ .../r16-0069-vStellungnahmeDr.JungFUBln.pdf.

179 Vgl. U. Zawatka-Gerlach, Bessere Chancen für Volksbegehren, in: Tsp. Nr. 19787 v. 16.1.2008. Siehe den ausgearbeiteten Änderungsantrag der Oppositionsfraktionen, abgedruckt in: AH Beschlußprotokoll Recht 16/21, S. 3 f. - „Gewürzt“ war diese Finanzierung durch eine Transparenzklausel: ,Sofern die Trägerin Einzelspenden erhalten hat, deren Gesamtwert 10.000 EUR übersteigt, so ist die Angabe des Namens und der Anschrift des Spenders sowie des Gesamtwerts gegenüber der für Inneres zuständigen Senatsverwaltung Voraussetzung der Kostenerstattung."

180 Vgl. Thüringer Landtag (Hrsg.), Bürgerantrag - Volksbegehren - Volksentscheid: Wie funktionierts?, o.O. 2004, S. 16.

181 Vgl. Magin/Eder, Direkte Demokratie (Fn. 173), S. 171.

182 Vgl AH Beschlußprotokoll Recht 16/20, S. 1 f. 
nes Volksbegehrens Geld bekämen, aber nicht die Gruppen, die dagegen sei$\mathrm{en}^{183}$.

Eine Woche später stimmte dann eine knappe Mehrheit der SPD-Fraktion gegen die Kostenerstattung, wie sie in dem zwischen allen Fraktionen verabredeten Gesetzentwurf vorgesehen war. Zum Argument des Ungleichgewichts kam hin$\mathrm{zu}, \mathrm{da} ß$ die Initiativen durch eine solche Finanzierung ,zu nahe an die Parteien gerückt“ würden ${ }^{184}$. Die SPD wurde für diese Entscheidung harsch gescholten. „Einen vernünftigen Grund für diese Blockade gibt es nicht“, tadelte der Redakteur des „Tagesspiegels“, der die Reformarbeiten begleitet hatte. Das Argument der Ungerechtigkeit sei vorgeschoben. Die SPD überlasse das Feld dem freien Spiel der Kräfte mit plutokratischen Effekten: „Soll sich ein erfolgreiches Volksbegehren nur noch leisten, vielleicht sogar kaufen können, der [sic] finanziell stark ist? Basisdemokratie - eine Sache für betuchte Leute und Privatunternehmen, die ihre Interessen am Parlament vorbei durchsetzen wollen. Das wäre absurd. Aber diesem Trend spielt die SPD mit ihrem dummen Trotz in die Hände. ${ }^{\text {“185 }}$ Als psychologischer Hintergrund wurden die Auseinandersetzungen um das laufende Volksbegehren gegen eine Flughafen-Schließung vermutet, wozu die Grünen treffend pointierten: Die Sozialdemokraten seien ,nachhaltig tempelhofisiert" ${ }^{\prime 186}$.

In der Sitzung des Rechtsausschusses am 6. Februar 2008 trug die SPD ihre beiden Begründungen noch einmal vor. Die inhaltliche Kritik, gerade auch vom Koalitionspartner, der Linksfraktion, verpuffte: „Gegner“ einer Initiative seien doch nicht die sachlich Andersdenkenden, sondern das „Abgeordnetenhaus “187; richtigerweise ist es sogar das ganze öffentlich geförderte politische Establishment ${ }^{188}$, verglichen mit dem eine Initiative auch mit Kostenerstattung immer noch wie David gegen Goliath anmuten würde. Und daß der gebotene Abstand zu den Parteien gewahrt bleibt, zeigt ein Blick auf die Quantitäten. Die nach einem Volksbegehren bzw. Volksentscheid ausgezahlten Beträge ${ }^{189}$ sind mit den Summen, die jenes Establishment als Parteienfinanzierung, Fraktionsfinanzierung und für die sogenannte Öffentlichkeitsarbeit der Regierung bekommt, überhaupt nicht zu vergleichen. Am Ende setzte die klassische repräsentativ-

183 Vgl. Ausschuss vertagt Abstimmung über Gesetzesnovelle zu Volksbegehren, in: Tsp. 19788 v. 17.1.2008.

184 Vgl. Volksbegehren: SPD will kein Geld erstatten, in: Tsp. Nr. 19795 v. 24.1.2008.

185 U. Zawatka-Gerlach, Demokratie gibt es nicht gratis, Tsp. 24.1.2008 (online).

186 Zit. bei K. Nölte, SPD lehnt Kosten für Demokratie ab, in: Neues Deutschland, 25.1.2008 (online).

187 So Abg. Lederer (Linksfraktion), AH Inhaltsprotokoll Recht 16/21, S. 3.

188 Vgl. O. Jung, zit. in: Volksbegehren: Rot-Rot gegen Kostenerstattung, in: Die Welt v. 8.2.2008 (online).

189 Vgl. die Zahlenbeispiele bei Thüringer Landtag, Bürgerantrag (Fn. 180), S. 16. 
demokratische Kaskade ein: Die SPD-Fraktion trug geschlossen die Mehrheitsentscheidung mit; die Linke beugte sich der Koalitionsdisziplin ${ }^{190}$, und die drei Oppositionsfraktionen wurden überstimmt ${ }^{191}$. Im Ergebnis wurde die Novelle des Ausführungsgesetzes ohne Kostenerstattung verabschiedet ${ }^{192}$. Der SPD war dieser Punkt so wichtig, daß sie dafür zum Abschluß der Reformarbeiten aus dem Konsens ausscherte, den man bei diesem Thema bisher eingehalten hatte. Dies war mitnichten nur eine „Lappalie“ - auch nicht innerhalb eines gesamten Reformpakets -, wie der ansonsten gerade in diesen Dingen scharfsichtige Abg. Lederer (Linksfraktion) meinte, sondern legte grundsätzliche Mißverständnisse und Fehleinschätzungen bei der größeren Regierungspartei offen und forderte zugleich weiteren Initiativen die alte große Anstrengung $a b$ - wobei die Fälle „Pro Reli“ und „Wasser“" erfreulicherweise alsbald bewiesen, daß es auch „ohne“ ging (wie ja etwa aus Bayern schon hinlänglich bekannt).

Von Vorschlägen, die über den Rahmen einer Verbesserung der Volksgesetzgebung hinausgingen, seien das obligatorische Verfassungs- und das fakultative Gesetzesreferendum erwähnt, die das Bündnis in den Reformprozeß einzubringen versuchte. Beide Instrumente wurden nur als verfassungspolitische Skizze festgehalten, aber nicht in dem Gesetzentwurf des Bündnisses ausformuliert. Für das obligatorische Verfassungsreferendum konnte das Bündnis immerhin zwei gute Gründe anführen: Die Verfassung war selbst 1995 erst „,nach Zustimmung in einer Volksabstimmung" in Kraft getreten (vgl. Art. 101 Abs. 1 S. 1 VvB), und es leuchtet ein, daß der Verabschiedungs- auch eine Änderungs-Zustimmungskompetenz entsprechen sollte. Ferner kennt die Verfassung seit 1995 bereits ein spezielles obligatorisches Verfassungsreferendum in Art. 100 S. 2, das bei der hier analysierten Reform erstmals zur Anwendung kommen sollte. „Diese Regelung sollte auf alle Verfassungsänderungen ausgeweitet werden.“193

Das fakultative Gesetzesreferendum sollten 40.000 Stimmberechtigte innerhalb von zwei Monaten nach Verabschiedung eines Gesetzes durch das Abgeordnetenhaus - aber vor dessen Inkrafttreten - herbeiführen können ${ }^{194}$. Zur Begründung entwarf das Bündnis das Szenario eines Konflikts zwischen dem Volk und seiner Vertretung: In diesem Falle gebe es bisher nur die Möglichkeit, ein

190 So ausdrücklich Abg. Lederer (Linksfraktion), AH Inhaltsprotokoll Recht 16/21, S. 3.

191 AH Beschlußprotokoll Recht 16/21, S. 4.

192 Dabei wurde den Initiatoren eine Transparenzpflicht auch ohne Kostenerstattung auferlegt, allerdings nur für Einzelspenden, die in ihrem Gesamtwert 50.000 Euro überstiegen (§ 40b AbstG i.d.F. v. 2008). Zweieinhalb Jahre später - nach dem „Pro Reli““-Volksentscheid - wurde diese Grenze auf ein Zehntel gesenkt, vgl. Jung, Berlin (Fn. 51), S. 153. Dieser Zahlen-Slalom: 10.000 - 50.000 - 5.000, spricht für eine gewisse Hektik des Gesetzgebers.

193 Berlin wird demokratischer (Fn. 12).

194 Vgl. Bündnis, Demokratie (Fn. 17). 
vom Parlament beschlossenes und in Kraft getretenes Gesetz im Wege der Volksgesetzgebung wieder abzuschaffen. Statt dessen den Bürgerinnen und Bürgern durch ein fakultatives Gesetzesreferendum eine Art „Vetorecht“ einzuräumen, sei wesentlich eleganter. „So können Konflikte durch frühes Reagieren minimiert werden. “195 Beim fakultativen Gesetzesreferendum sollte ebenso wie beim obligatorischen Verfassungsreferendum die einfache Mehrheit der abgegebenen Stimmen entscheiden.

Beide Instrumente waren in den anderen hier betrachteten Entwürfen nicht enthalten ${ }^{196}$. Im parlamentarischen Prozeß der Reform der direkten Demokratie in Berlin wurden jene beiden verfassungspolitischen Neuerungen - soweit ersichtlich - nicht in Erwägung gezogen.

Vor allem die Einführung des fakultativen Gesetzesreferendums wäre eine wirklich wegweisende Reform gewesen. In eklatantem Unterschied zu seiner intensiven Nutzung in der Schweiz ist dieses Instrument in Deutschland normativ nur marginal zu finden ${ }^{197}$ und wurde wissenschaftlich „traditionell“" vernachlässigt, obwohl seine - höchst seltene - Praxis hochinteressant ist ${ }^{198}$. Es ist Frank Deckers Verdienst, seit einigen Jahren mit großem Engagement den Blick auf dieses Instrument gelenkt zu haben, wenngleich er das fakultative Gesetzesreferendum leider in eine Gegenposition zur Volksgesetzgebung bringt, obwohl sich beide Instrumente, wie wiederum die Schweiz zeigt, vortrefflich ergänzen. $\mathrm{Zu}$ Recht weist Decker darauf hin, daß bei den meisten Versuchen der Volksgesetzgebung in den deutschen Ländern die Innovationsfunktion dieses Verfahrens gerade nicht zur Geltung kommt ${ }^{199}$. Die Initiatoren versuchen vielmehr schlicht, vorangegangene Beschlüsse von Regierungen oder Parlamenten rückgängig zu machen. In der Tat ist die Volksgesetzgebung eigentlich nur nötig, wenn das repräsentativ-demokratische System nicht „liefert“, also gar nichts da ist, gegen das man das Referendum ergreifen könnte ${ }^{200}$.

195 Berlin wird demokratischer (Fn. 12). - In diesem Kommentar ist übrigens - vermutlich durch ein Versehen - von 50.000 benötigten Unterschriften die Rede.

196 Die PDS wollte 2000 lediglich das bestehende spezielle obligatorische Verfassungsreferendum auf zwei weitere einschlägige Artikel ausdehnen (vgl. Drs. 14/655 v. 14.9.2000, S. 2 (Art. I Nr. 5 [zu Art. 100 S. 2])), aber nicht die gesamte Verfassung referendumspflichtig machen.

197 Es existiert auf Landesebene in Rheinland-Pfalz (seit 1947) und neuerdings für einen Spezialfall in Hamburg (seit 2008), vgl. v. Arnauld, „Refolution“ (Fn. 75), S. $117 \mathrm{f}$.

198 Vgl. O. Jung, Wenn der Souverän sich räuspert ... Vorwirkungen direktdemokratischer Korrekturmöglichkeiten, dargestellt an Beispielen aus Nordrhein-Westfalen, Niedersachsen und Rheinland-Pfalz, in: JzStVWiss 8 (1995), S. 107-176 (136-161, 170-176).

199 Vgl. F. Decker, Volksgesetzgebung oder Volksveto? Überlegungen zur institutionellen Ausgestaltung der Direktdemokratie in der Bundesrepublik, in: JdD 2 (2010), S. 37-62 (43 ff.).

200 Ein bekannter Fall betraf die Ermöglichung der kommunalen Direktdemokratie in Bayern im Wege der Volksgesetzgebung, vgl. O. Jung, Der Volksentscheid über die Einführung 
Doch das ist nicht die Situation in Berlin. Das Problem dieser Stadt ist nicht, daß „die da oben“ " nichts tun würden - sie tun eher zu viel -, sondern daß sie das Falsche tun, oder wenn es doch richtig sein sollte, unwillig oder unfähig sind, es „denen da unten“ $z u$ vermitteln ${ }^{201}$. Tatsächlich betrafen alle drei Volksentscheide in Berlin nach der Reform 2006 ,oben“ getroffene Entscheidungen, die heftige Ablehnung provozierten: eine Flughafenschließung (Fall „Tempelhof““ 2008), die Einführung eines neuen Pflichtfachs Ethik an den Schulen (Fall „Pro Reli““ 2009) und eine Privatisierung im Bereich der Daseinsvorsorge (Fall „Wasser“ 2011). Aus der Zeit vor 2006 könnte man noch das Volksbegehren gegen die „Rechtschreibreform“ dazu nehmen, das sich ausdrücklich gegen eine mißlungene oder zumindest unzureichend vermittelte Reform wandte. In keinem dieser Fälle war Innovation gefordert, es ging vielmehr einfach darum, jene umstrittenen staatlichen Entscheidungen auf den basisdemokratischen Prüfstand zu stellen.

Für solche Konstellationen nach dem Referendum zu rufen, entspringt keinem Purismus direktdemokratischer Theorie. Vielmehr bedeutet die aktuelle Situation für jede Initiative zwei massive Handicaps. Erstens: Sie muß im Verfahren der Volksgesetzgebung einen Gesetzentwurf ausarbeiten bzw. die Nebenform der „anderen Vorlage“ erarbeiten und eine verfassungsrechtliche bzw. gar -gerichtliche Prüfung mit allen Fallstricken bestehen, statt daß man ihr einfach die Möglichkeit gibt, die „oben“ beschlossene Problemlösung dem Urteil des Volkes zu unterstellen, ob es mit dieser Entscheidung seiner Vertreter bzw. seiner Regierung zufrieden oder zumindest einverstanden ist oder nicht. Zweites Handicap: Alle Systeme mit ausgebauter direkter Demokratie differenzieren in Bezug auf die Volksgesetzgebung („Gaspedal“) und das fakultative Gesetzesreferendum („Bremse“) bei den Verfahrensanforderungen. Wer innovativ neue Regeln für alle verbindlich einführen will, muß von vornherein mehr Unterstützung aufbringen als derjenige, der eine Parlamentsentscheidung auf den Prüfstand der Billigung des Volkes stellen will - wobei es im ,schlimmsten Fall“ beim status quo verbleibt. Die Schweiz, die Weimarer Reichsverfassung und die Landesverfassungen von Rheinland-Pfalz und Hamburg belegen dies. Indem Berlin wie fast alle anderen Bundesländer ein fakultatives Gesetzesreferendum überhaupt nicht vorsieht, entfällt auch jene Verfahrensprivilegierung. Es handelt sich im

des kommunalen Bürgerentscheids in Bayern am 1. Oktober 1995, in: JzStVWiss 9 (1996), S. 191-272.

201 Man denke nur an den Exponenten des einen bundespolitischen Lagers, der eine „BastaPolitik“ zu treiben versuchte, und seine Nachfolgerin der anderen Couleur, die vom „Durchregieren“ redete und inzwischen ihre Politik mit Vorliebe für alternativlos erklärt. Dies sind die Spitzen eines politischen Systems, das natürlich auch die Berliner Landespolitik prägt. 
Grunde um eine Nivellierung der Anforderungen nach oben. Dies ist zutiefst unfair $^{202}$.

Wenn man sich vorstellt, die Berliner hätten über ein Volksbegehren mit Fünf-Prozent-Hürde die „Rechtschreibreform“ billigen oder verwerfen oder sie hätten mit einer 3,5-Prozent-Hürde in den letzten drei Streitfällen Referenden über die Flughafenschließung, das neue Pflichtfach Ethik und die Privatisierung der Wasserbetriebe herbeiführen können, wird plötzlich sichtbar, welche Perspektiven bürgerlicher Selbstbestimmung eine institutionell wohlgeordnete direkte Demokratie eröffnen könnte. Damit hätte Berlin für Deutschland 2006 noch mehr als Innovation leisten können, als es Schleswig-Holstein 1989 tat. So blieb man eben doch mit der herkömmlichen Verbesserungspolitik in den alten Geleisen.

\subsubsection{Zur Einschätzung der Reformschritte insgesamt}

Überblickt man die einzelnen Reformschritte insgesamt, stellt sich fortschreitend Enttäuschung ein. Gemessen am bisherigen Regelwerk der direkten Demokratie in Berlin bringt die Reform zwar große Fortschritte; dies zu verkennen wäre töricht. Doch die ansehnlichen Verbesserungen nach innerberlinischem Maßstab verlieren an Glanz, wenn man realisiert, wie niedrig der Ausgangspunkt lag. Über weite Strecken gleicht die Reform nur aus, was 1995 versäumt wurde und Berlin im Bundesländer-Vergleich zum Schlußlicht machte. So wundert auch nicht, daß Berlin es selbst mit dieser Reform nur ins vordere bzw. mittlere Drittel der Bundesländer ,geschafft“ hat ${ }^{203}$. Die bloß symbolische Politik bei der Ein-

202 Dies wird näher ausgeführt bei Jung, Berlin (Fn. 51), S. 43 ff. - Die gesamte Problematik übergehen M. Kloepfer/F. Schärdel, Die Perspektiven der Volksgesetzgebung - Rechtsprobleme der künftigen Gestaltung von Volksentscheiden insbesondere am Beispiel Berlins -, in: DVB1. 2008, S. 1333-1340. Auch Pestalozza beschränkt sich verfassungspolitisch darauf, für das obligatorische Verfassungsreferendum zu plädieren (Auf gutem Weg [Fn. 33], S. 314 f.).

203 Der Fachverband Mehr Demokratie e.V. beurteilte die Reform, obwohl sie ja ein bißchen „sein Kind“" war, recht kritisch: Berlin habe nun „eine annehmbare Regelung auf Landesebene“, urteilte er im Dezember 2006. Dies ergab die Note ,ausreichend $(3,8)$ " und Platz 4 im Bundesländer-Ranking, vgl. F. Rehmet/K. Flothmann/T. Weber, Zweites Volksentscheid-Ranking. Länder und Gemeinden im Demokratie-Vergleich, hrsg. v. Mehr Demokratie e.V., Berlin 2007, S. 29. Daß Berlin speziell „Brandenburg im VolksentscheidRanking durch mutige Reformen weit hinter sich" habe lassen können - dieses erhielt die Note „mangelhaft $(4,3)^{\text {“ } ~ u n d ~ k a m ~ a u f ~ P l a t z ~} 11$ - (a.a.O., S. 36), tröstete da nur wenig. Knapp vier Jahre und zwei Volksentscheide später hatte sich die Einschätzung des Berli-

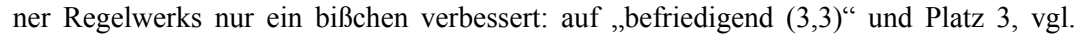
Rehmet/Weber/Gogolin, Volksentscheids-Ranking 2010 (Fn. 149), S. 29. Daß Berlin da- 
führung der verfassungsändernden Volksgesetzgebung und das unbestellte Reformfeld der Kostenerstattung lassen keine bessere Bewertung zu.

Diese skeptische Einschätzung impliziert keinen Vorwurf an die handelnden Politiker. Kühne, geschlossene Entwürfe vorzulegen bzw. ein gesetzgeberisches Werk systematisch zu kritisieren, ist das eine - verfassungsändernde parlamentarische Mehrheiten für eine weitergehende Reform zu organisieren ein anderes. Wenn mehr nicht „machbar“ war, wie die Verantwortlichen sagen, ist dies zu akzeptieren. Freilich sollte dann auch allzu dick aufgetragenes Eigenlob der Reformer unterbleiben.

\subsection{Der Geist und Stil der Reform}

Hier sollen einige Beobachtungen aus den Debatten des Abgeordnetenhauses während der zwölf Monate von Juni 2005 bis Mai 2006 systematisch zusammengestellt werden. Zwar beziehen sich die Beiträge zunächst unmittelbar auf die erste Direkte-Demokratie-Reform dieser Zeit - die Einführung von Bürgerentscheiden auf Bezirksebene -, aber auch jene Reform wurde ja bereits mit der Perspektive einer entsprechenden Verbesserung der direkten Demokratie auf Landesebene diskutiert und beschlossen.

Auf fällt erstens, wie sehr „Weimar als Erfahrung und Argument“204 versunken bzw. verschwunden ist. Nur zweimal wurde „Weimar“ überhaupt angesprochen, beidesmal von Sozialdemokraten. Während der eine die geringe quantitative Nutzung der Volksgesetzgebung und den negativen Ausfall der Volksentscheide seinerzeit dahin zusammenfaßte, daß selbst in der Weimarer Republik „die Bürger manches Mal schlauer (waren), als viele von uns es ihnen stets unterstellten oder wie es die Väter des Grundgesetzes sahen“،205 - also eine eindeutig revisionistische Position einnahm ${ }^{206}$-, sprach der andere zwar von „der histo-

mit im Bundesländer-Ranking eine „Spitzenstellung“ einnehme (ebda.), will nicht recht einleuchten.

204 Vgl. Weimar als Erfahrung und Argument. Ansprachen und Referate anläßlich der Feier des 25jährigen Bestehens der Kommission für Geschichte des Parlamentarismus und der politischen Parteien, o.O. 1977. Siehe eine Generation weiter den Sammelband von C. Gusy (Hrsg.), Weimars lange Schatten - „Weimar“ als Argument nach 1945, BadenBaden 2003 (Interdisziplinäre Studien zu Recht und Staat Bd. 29), und darin den Beitrag von A. Wirsching, Konstruktion und Erosion: Weimarer Argumente gegen Volksbegehren und Volksentscheid, S. 335-353.

205 Abg. Bernd Schimmler (SPD), AH 2.6.2005, S. 5835 C.

206 Vgl. C. Schwieger, Volksgesetzgebung in Deutschland. Der wissenschaftliche Umgang mit plebiszitärer Gesetzgebung auf Reichs- und Bundesebene in Weimarer Republik, Drittem Reich und Bundesrepublik Deutschland (1919-2002), Berlin 2005 (Tübinger Schriften zum Staats- und Verwaltungsrecht Bd. 71), S. 351-378. 
rischen Erfahrung mit einem schwachen Parlament, insbesondere in der Weimarer Republik“, fügte aber sofort hinzu: „Das ist kein Vorwurf an Protagonisten von direkter Demokratie، ${ }^{6207}$.

Bemerkenswert erscheint ferner, in welchem Maße jene Debatten dem Geist des Wettbewerbsföderalismus huldigten. Obwohl die Antwort auf die Frage, ob bzw. in welchem Maße die Bürgerinnen und Bürger unmittelbar-demokratisch sollen entscheiden können, verfassungsrechtlich ,im freien, durch bundesrechtliche Normen nicht beschränkten Ermessen der Länder" steht ${ }^{208}$, behandelten die Redner hier die Bundesländer wie einen großen Normen-Markt, stellten Rankings zwischen den Ländern auf bzw. übernahmen solche, klagten über Berlin als „Bummelletzter in dieser Republik, was die Beteiligungsmöglichkeiten der Bürger angeht ${ }^{\text {‘209 }}$, und daß das Land „die rote Laterne“" trage ${ }^{210}$, und strebten nach vorne, wenn vielleicht nicht gleich an die Spitze, so doch zumindest auf vordere Plätze ${ }^{211}$.

Am meisten erstaunt, wie sehr in diesen Debatten die Erfahrung „Trumpf“ war. Es ging um die bisherigen Erfahrungen mit direkter Demokratie in Berlin selbst und um die Erfahrungen in anderen Bundesländern ${ }^{212}$, von denen man wie es offen hieß - „lernen“ solle ${ }^{213}$. Dies ersparte natürlich nicht die weitere Diskussion, denn die angesprochenen Erfahrungen lagen ja nicht einfach und unzweideutig zutage. Daß direkte Demokratie in Berlin bislang kaum praktiziert worden war, konnte man verschieden erklären: Waren die Verfahrenshürden zu hoch $^{214}$, oder waren die einschlägigen Projekte nicht attraktiv genug für ein mas-

207 Abg. Christian Gaebler (SPD), AH 4.5.2006, S. 7344 B.

208 BVerfG, Beschluß v. 24.3.1982, BVerfGE 60, 175 (208).

209 Vgl. Abg. Ritzmann (FDP), AH 2.6.2005, S. 5841 D; dens., AH 16.6.2005, S. 5950 D.

210 Vgl. Abg. Frank Zimmermann (SPD), AH 24.11.2005, S. 6548 A.

211 Vgl. Abg. Jeannette Martins (Bündnis 90/Die Grünen), AH 16.6.2005, S. 5949 B; Abg. Ritzmann (FDP), AH 16.6.2005, S. 5950 D; Abg. Ratzmann (Bündnis 90/Die Grünen), AH 24.11.2005, S. 6547 A; Abg. Zimmermann (SPD), AH 24.11.2005, S. 6548 A; Abg. Lederer (Linkspartei.PDS), AH 24.11.2005, S. 6549 D.

212 Vgl. Abg. Schimmler (SPD), AH 2.6.2005, S. 5835 CD (Hamburg), 5836A (Bayern); Abg. Ritzmann (FDP), AH 2.6.2005, S. 5841 D (Bayern, Hamburg); Abg. Martins (Bündnis 90/Die Grünen), AH 16.6.2005, S. 5949 BC (Bayern, Hamburg); Abg. Ritzmann (FDP), AH 16.6.2005, S. 5950 D (Bayern).

213 Vgl. Innensenator Ehrhart Körting (SPD), AH 2.6.2005, S. 5843 A: „Ich meine, man sollte von den Erfahrungen anderer Bundesländer lernen." Ferner Abg. Zimmermann (SPD), AH 24.11.2005, S. 6548 B; Abg. Gaebler (SPD), AH 4.5.2006, S. 7344 B („Wie sind dort die Regelungen? Wie werden sie genutzt? Was sind vielleicht Hindernisse, daß sie stärker genutzt werden?“); Abg. Ratzmann (Bündnis 90/Die Grünen), AH 4.5.2006, S. 7345 D.

214 So räumte der Abg. Frank Henkel (CDU) ein, ihm sei im Zusammenhang des Bürgerbegehrens gegen die Umbenennung der Kochstraße in Rudi-Dutschke-Straße ,deutlich geworden, daß für die Elemente der direkten Bürgerbeteiligung auf Landesebene die 
sendemokratisches Verfahren? ${ }^{215}$ Auch in den anderen Bundesländern sind die Fälle eher die Ausnahme, in denen man - ceteris paribus - z.B. den prohibitiven Effekt mancher Regelwerke zeigen $\mathrm{kann}^{216}$. Aber wichtig sind hier vor allem die Anerkennung des Grundsatzes, daß Institutionen den ins Auge gefaßten Problemen adäquat $\operatorname{sein}^{217}$ und daß sie „funktionieren“ müssen im Sinne ihrer Eignung, jene Probleme auch zu lösen ${ }^{218}$, und dazu der Ansatz bei der Erfahrung, bei den Lehren der Wirklichkeit. Die Zeiten des deduktiven Argumentierens etwa aus dem Wesen der Demokratie oder aus dem Begriff des Volksentscheids waren vorbei.

Mit „Erfahrungen“ hatte auch der stark tentative Zug dieser Reform zu tun. Wo sie noch nicht vorlägen, solle man sie jetzt eben gewinnen, und so wurden die neuen Regeln bewußt als vorläufig konzipiert und sollten nach einer Überprüfung gegebenenfalls weitere Reformschritte unternommen werden ${ }^{219}$ - welcher Unterschied zu den früheren (ideologischen) Gewißheiten in dieser Materie.

Festhaltenswert sind auch die in den Debatten geäußerten Motive und Ziele der Reform. Eher negativ formuliert wollte man den Problemen des Parteienstaa-

Quoren nach aktueller Rechtslage viel zu hoch sind - so hoch, daß sie quasi unüberwindbare Hürden darstellen“ (AH 4.5.2006, S. 7343 A).

215 Vgl. Abg. Zimmermann (SPD), AH 24.11.2005, S. 6547 D; Abg. Michael Braun (CDU), AH 24.11.2005, S. 6549 A.

216 Siehe die Volksbegehren für die Erhaltung des Buß- und Bettages in Schleswig-Holstein 1996/97 einerseits und in Rheinland-Pfalz 1998 andererseits, vgl. Schimmer, Ihre Stimme (Fn. 148), S. 286; O. Jung, Bürgerbeteiligung - ohne Risiken und Nebenwirkungen? hrsg. von der Landeszentrale für politische Bildung Rheinland-Pfalz, Mainz 2002, S. 9 ff.

217 Vgl. H.H. v. Arnim (Hrsg.), Adäquate Institutionen: Voraussetzungen für „gute“ und bürgernahe Politik? Vorträge auf dem 2. Speyerer Demokratie-Forum vom 14. bis 16. Oktober 1998 an der Deutschen Hochschule für Verwaltungswissenschaften Speyer, Berlin 1999 (Schriftenreihe der Hochschule Speyer Bd. 133).

218 Vgl. Jung, Quorenproblem (Fn. 82), S. 894.

219 Vgl. Innensenator Körting (SPD), AH 2.6.2005, S. 5843 B: Er ,glaube, man kann es einfach erst mal machen und Erfahrungen machen und aus den Erfahrungen heraus sehen, wo es kneift und wo man es ggf. noch einmal korrigieren muß“. Siehe auch Abg. Lederer (Linkspartei.PDS), AH 4.5.2006, S. 7342 A: „Wir werden schauen müssen, wie sich in den nächsten Jahren dieses Instrument bewährt, ob es sich bewährt, ob die Hürden tatsächlich nicht noch weiter abgesenkt werden müssen, um die Mitwirkung der Berlinerinnen und Berliner real möglich zu machen. Wenn wir in fünf Jahren feststellen, daß das Instrument nicht genutzt wird, dann sind wir gefragt. Dann liegt es gewiß nicht an den Bürgerinnen und Bürgern dieser Stadt, sondern dann liegt es an dem Parlament und daran, daß zu hohe Hürden in diese Verfassung geschrieben worden sind. Und dann werden wir das ändern müssen." Zustimmend Abg. Gaebler (SPD), AH 4.5.2006, S. 7344 CD: „Natürlich kann man in der nächsten Legislaturperiode sehen, was aus den Neuerungen folgt, die eingeführt worden sind, wie sie sich umsetzen, was es eventuell noch an Problemen gibt und wie man gegebenenfalls an einzelnen Stellen weiter vorangehen kann. Dies ist ein schrittweiser Prozeß, der heute weder abgeschlossen noch vervollkommnet ist.“ Ferner Abg. Ratzmann (Bündnis 90/Die Grünen), AH 4.5.2006, S. 7345 D; Abg. Ritzmann (FDP), AH 4.5.2006, S. 7347 CD. 
tes etwas beikommen ${ }^{220}$, der wachsenden Politik-, Politiker- und Parlamentsverdrossenheit entgegenwirken ${ }^{221}$ und vor allem gegen das verbreitete Gefühl, den Entscheidungen der Politik ,ausgeliefert zu sein“, etwas unternehmen ${ }^{222}$. Positiv erhoffte man sich einen qualitativen Sprung in der politischen Entscheidungskul$\operatorname{tur}^{223}$, ja nicht weniger als „eine neue demokratische Kultur in diesem Land“ überhaupt $\mathrm{t}^{224}$.

Gewiß läßt sich gegen eine solche Debatten-Analyse einiges einwenden. Das beginnt schon immanent: Vergleich - war es nur ein „Ausrutscher“, wenn der Abg. Alexander Ritzmann (FDP) anaphorisch betonte, daß es ,in Bayern, in Nordrhein-Westfalen, in Hessen eine lebendige direkte Demokratie“ gebe ${ }^{225}$, wo doch in letztgenanntem Land in puncto Volksgesetzgebung - und darum ging es gerade - nichts als eine Wüste zu sehen ist? Und wenn das schon im Bundesländer-Vergleich passierte, was ist dann mit den internationalen Erfahrungen vor allem aus den Referenzländern der direkten Demokratie, der Schweiz und den US-Bundesstaaten? Im allgemeinen wurde über sie geschwiegen, einmal wurde auf sie pauschal Bezug genommen ${ }^{226}$, und der FDP-Dissident der II. Lesung, der in Kalifornien zum Renegaten geworden war - hatte er Feldforschung vor Ort getrieben oder doch eher eine politische „Schnupper-Tour“ unternommen ${ }^{227}$ ? Erfahrung - wollte man wirklich ausprobieren, ob die Kombination von interner Qualifikation (Zweidrittel-Mehrheit der Abstimmenden) und 50prozentigem Zu-

220 Vgl. Abg. Schimmler (SPD), AH 2.6.2005, S. 5835 D.

221 Vgl. Abg. Peter-Rudolf Zotl (PDS), AH 2.6.2005, S. 5838 B; Abg. Ritzmann (FDP), AH 2.6.2005, S. 5841 D; Abg. Gaebler (SPD), AH, 4.5.2006, S. 7343 C.

222 Vgl. Abg. Schimmler (SPD), AH 16.6.2005, S. 5946 D.

223 Vgl. Abg. Zotl (PDS), AH 2.6.2005, S. 5838 A, D; ders., AH 16.6.2005, S. 5948 D.

224 Vgl. Abg. Ritzmann (FDP), AH 2.6.2005, S. 5842 B.

225 AH 4.5.2006, S. 7347 C.

226 Vgl. Abg. Ritzmann (FDP), AH 2.6.2005, S. 5841 D.

227 Vgl. Abg. Axel Hahn (FDP), AH 18.5.2006, S. 7431 BC: „Ich hatte in dieser Legislaturperiode die Gelegenheit, mit der Checkpoint-Charlie-Stiftung nach Kalifornien zu reisen und das politische System dort kennen zu lernen. Ich bin dorthin als Befürworter von Volksabstimmungen gefahren und mit großen Zweifeln heimgekehrt. Der Bundesstaat Kalifornien ist teilweise durch Volksabstimmungen, die er viel länger kennt als wir, an den Rand seiner Regierungs-, Handlungs- und Zahlungsfähigkeit gekommen. Ich möchte nicht, daß in dem schwierigen Land Berlin eine ähnliche Situation eintritt. Deshalb meine ich, daß bei Volksabstimmungen eine Themenbegrenzung bestehen sollte." - Siehe zum Problem neuerdings H.K. Heußner, Die Krise Kaliforniens - Die Schuld der direkten Demokratie? In: JdD 3 (2011), S. 175-233; ferner aus der älteren Literatur M. Bauer, Direkte Demokratie und Finanzpolitik in den USA. Volksabstimmungen über Haushaltsfragen, Steuern und Verschuldung in Kalifornien, phil. Diss. Erlangen-Nürnberg 1997; U. Glaser, Direkte Demokratie als politisches Routineverfahren. Volksabstimmungen in den USA und in Kalifornien, Erlangen/Jena 1997 (Erlanger Studien Bd. 112); N. v. Arx, Ähnlich, aber anders. Die Volksinitiative in Kalifornien und in der Schweiz, Genf/Basel/ München 2002 (Collection genevoise: Démocratie directe). 
stimmungsquorum bei der verfassungsändernden Volksgesetzgebung, von der alle Fachleute sagen, daß sie nur symbolische Politik sei, in Berlin vielleicht doch funktioniere? Tentativ - waren das nicht einfach die Argumentationsfiguren jener „Progressiven“, die bei der Kompromißsuche ihrem Gefühl nach zu viele Konzessionen gemacht hatten und nun sich und ihre Anhänger zu trösten versuchten?

Darüber hinaus könnte man grundsätzlich fragen, was eigentlich eine solche Analyse erfaßt: die tatsächlichen Auseinandersetzungen zwischen den verschiedenen Lagern, bis dann ein Kompromiß gefunden wurde, oder doch eher „Fensterreden" in Feierlaune, mit denen der formelle Abschluß der Reform politischtheatralisch inszeniert wurde? Und wenn man die Argumente mustert - dachte so wirklich die politische Klasse Berlins, oder war das genau jener Diskurs, den der Zeitgeist, um nicht zu sagen: die „political correctness“, zu diesem Thema zuließ?

Doch bei aller Skepsis sind diese Debatten und wie sie geführt wurden, nicht ohne Gewicht. Juristisch: Jene Debatten sind immerhin die Grundlage einer genetischen Interpretation, wenn es um die Auslegung, womöglich im Verfassungsprozeß, der neuen Regeln geht. Historisch: Auch wenn es nur der politisch korrekte Diskurs gewesen sein sollte, ist doch bemerkenswert, wie diese ,political correctness“ 2005/06 aussah und daß das Abgeordnetenhaus sich ihr fügte. Politisch: Gerade im parlamentarischen Wettbewerb der Parteien kann man hinter einen bestimmten Debattenstand nicht so ohne weiteres zurück. Ein Argument, das einmal aufgegeben wurde, läßt sich schlecht wieder vorbringen. Und von einer Konzession, die einmal gemacht wurde, kommt man nur schwer wieder weg.

Wenn freilich jene Skepsis sich als unbegründet erweisen sollte, könnte sich vielleicht in der Zukunft herausstellen, daß der Geist und der Stil der Reform größeren Belang hatten als diese oder jene einzelne Regelung.

\section{Schlu $\beta$}

Berlin ist, wie die Geschichte seit dem Krieg zeigt, für direkte Demokratie ein steiniger Boden. $\mathrm{Zu}$ dieser generellen Beobachtung paßt das Detail, daß die hier analysierte Reform der direkten Demokratie nicht einfach als Umsetzung der einschlägigen Koalitionsabrede von 2002 geschah. Der Impetus der politischen Elite kam ganz woanders her, nämlich von dem Wunsch, das stadtstaatliche Senatsprinzip (vor allem bei der Regierungsbildung) durch das Kanzlerprinzip zu ersetzen und aus dem „Regierenden Bürgermeister“ sozusagen einen „Ministerpräsidenten“ zu machen. Die Reform der direkten Demokratie gelang dann aufgrund eines klassischen politischen „Deals“ der Parteien im Abgeordnetenhaus. 
Die erforderliche Verfassungsänderung wurde interfraktionell ausgehandelt, als All-Parteien-Vorlage ins Abgeordnetenhaus eingebracht und dort einmütig verabschiedet. Intransparenz und fehlende Diskursivität kennzeichneten dieses Verfahren. Da die Parteien für die anschließend notwendige Volksabstimmung auch so gut wie keinen Abstimmungskampf führten, sondern letztlich von den Bürgerinnen und Bürgern eine plebiszitäre Akklamation zu dieser überhaupt nicht vermittelten Reform verlangten, wäre das Referendum nachgerade unpolitisch abgelaufen, wenn da nicht eine Bürgerbewegung für mehr direkte Demokratie sich eingeschaltet hätte mit dem hohen Ziel, daß die Berlinerinnen und Berliner am 17. September ,eine bewußte Entscheidung treffen“ sollten. Die Kampagne dieses „Bündnisses für Direkte Demokratie“ gab einerseits ein großartiges Zeichen von Engagement, andererseits war, was für die kleine Schar der Aktivisten eine riesige Anstrengung bedeutete, bezogen auf die Millionenstadt und verglichen mit dem gleichzeitigen, professionell geführten Wahlkampf, eben doch fast nichts.

Bei der Volksabstimmung wurde die Reform der direkten Demokratie eindrucksvoll angenommen; mehr als vier Fünftel der Abstimmenden votierten mit „Ja“. Freilich spielte hier auch das spezielle, quorenlose Regelwerk eine Rolle. Die vom Parlament für künftige verfassungsändernde Volksgesetzgebung aufgestellten Hürden hätte die jetzige Vorlage (hypothetisch) nicht genommen.

Inhaltlich brachte die Reform, gemessen am bisherigen Regelwerk der direkten Demokratie, zwar große Fortschritte; doch diese Verbesserungen verlieren an Glanz, wenn man realisiert, wie niedrig der Ausgangspunkt lag. Über weite Strecken glich die Reform nur aus, was bei der Verfassungsgebung 1995 versäumt wurde und Berlin im Bundesländer-Vergleich zum Schlußlicht machte. So wundert auch nicht, daß Berlin es selbst mit dieser Reform nur ins vordere bzw. mittlere Drittel der Bundesländer ,geschafft“ hat. Verläßt man die normative Ebene und fragt nach den Chancen in der Wirklichkeit, direkte Demokratie in Berlin erfolgreich zu praktizieren, fällt die Antwort immer noch ziemlich skeptisch aus, vor allem wenn man die bloß symbolische Politik bei der Einführung der verfassungsändernden Volksgesetzgebung und die unbestellten Reformfelder - Kosten, Referenden - bedenkt.

Bemerkenswert sind noch Geist und Stil der Reform. Der Schatten „Weimars“ spielte kaum mehr eine Rolle. Statt dessen huldigten die Reformer dem Geist des Wettbewerbsföderalismus, fragten nach den gegenwärtigen Erfahrungen in anderen Bundesländern und legten ihr Reformprojekt bewußt tentativ an. 
